\title{
Active Control of Flow Separation on a High-Lift System with Slotted Flap at High Reynolds Number
}

\author{
Abdollah Khodadoust ${ }^{*}$ and Anthony Washburn ${ }^{\dagger}$
}

The NASA Energy Efficient Transport (EET) airfoil was tested at NASA Langley's LowTurbulence Pressure Tunnel (LTPT) to assess the effectiveness of distributed Active Flow Control (AFC) concepts on a high-lift system at flight scale Reynolds numbers for a medium-sized transport. The test results indicate presence of strong Reynolds number effects on the high-lift system with the AFC operational, implying the importance of flightscale testing for implementation of such systems during design of future flight vehicles with AFC. This paper describes the wind tunnel test results obtained at the LTPT for the EET high-lift system for various AFC concepts examined on this airfoil.

$\begin{array}{ll}\alpha & \text { angle of attack } \\ c & \text { chord length } \\ C_{L} & \text { lift coefficient } \\ C_{L \text { max }} & \text { maximum lift coefficient } \\ C_{p} & \text { pressure coefficient } \\ C_{\mu} & \text { slot momentum coefficient }=2(h / c)\left(\rho_{j} / \rho_{\infty}\right)\left(U_{j} / U_{\infty}\right)^{2} \\ \delta_{\text {flap }} & \text { flap deflection angle } \\ f & \text { oscillation frequency, Hz } \\ \mathrm{F}^{+} & \text {dimensionless frequency }=f . x_{t . e .} / U_{\infty} \\ h & \text { actuator slot width } \\ \mathrm{M} & \text { Mach number } \\ \rho_{j} / \rho_{\infty} & \text { ratio of jet actuator density to free stream density } \\ U \\ j\end{array}$

\section{Introduction}

Application of Active Flow Control on flight surfaces has been the subject of research and development for many years. Recent developments have shown significant gains can be achieved through distribution of AFC actuators on a lifting surface. The concept has been demonstrated on representative high-lift geometries in wind tunnel tests employing both 2-D and 3-D configurations ${ }^{1}$. Application of distributed Active Flow Control, or AFC, has shown significant potential with both steady and pulsed actuators.

\footnotetext{
* Manager, AeroSciences, Integrated Defense Systems, The Boeing Company, AIAA Associate Fellow

${ }^{\dagger}$ Head, Flow Physics and Control Branch, NASA Langley Research Center, AIAA Senior Member 
Nearly all testing done to-date has been carried out in atmospheric wind tunnels where Reynolds number scaling fell below what is expected on a medium-sized transport in high-lift configuration during approach or take off. The tests conducted for evaluation of AFC effects at high Reynolds numbers are summarized in Reference 2 through Reference 9. With the exception of the NACA $0015^{2}$ and the EET ${ }^{9}$ airfoils configured for cruise or configured with a simple hinged flap, the remainder of the citations ${ }^{3-8}$ report on the results for a generic bump. The lift performance of the NACA 0015 cruise airfoil exhibited little sensitivity to RN variation, with or without application of AFC. The lift performance of the EET airfoil in cruise configuration was reported to exhibit sensitivity to RN variation, primarily attributed to flow blockage resulting from using a large-chord model. Overall, results from these studies indicate performance gains at high RN conditions are achievable for the configurations examined.

The aerodynamic performance of a modern high-lift system employing a slotted flap can be quite sensitive to changes in Reynolds number, and the effects are well documented in the literature. The wind tunnel test described in this paper is the first attempt to obtain high-quality aerodynamic measurements on a high-lift system with a single-segment slotted flap at flight-scale Reynolds number conditions. The effort was carried out in order to address two areas of need: to obtain a database of high-quality aerodynamic measurements that can be used for validation and calibration of emerging computational tools used for design of future-generation subsonic transports that will utilize the AFC concept, and to assess whether Reynolds number scaling is critical for modern high-lift systems that employ the AFC concept. The comparison of these experimental results to numerical simulation is described in a companion article ${ }^{10}$. The model and instrumentation are briefly described in the next section, followed by the test results.

\section{Model, Actuator and Wind Tunnel Description}

Wind Tunnel Model - The EET airfoil utilized in this study was chosen for two reasons:

Large database of aerodynamic performance was available from the conventional multi-element version of the EET model that NASA has previously tested.

The simplified high-lift EET airfoil with a drooped leading edge and simple hinged flap, shown in Figure 1, was designed and fabricated by NASA to study active flow control concepts. This activity was spurred by a system study performed by Boeing in $1999^{11}$, which showed the potential for weight and cost savings by eliminating the hardware required for a conventional high-lift flap and slat system currently used on commercial aircraft. This configuration was tested by NASA in the LTPT and the preliminary results were published in Reference 9.

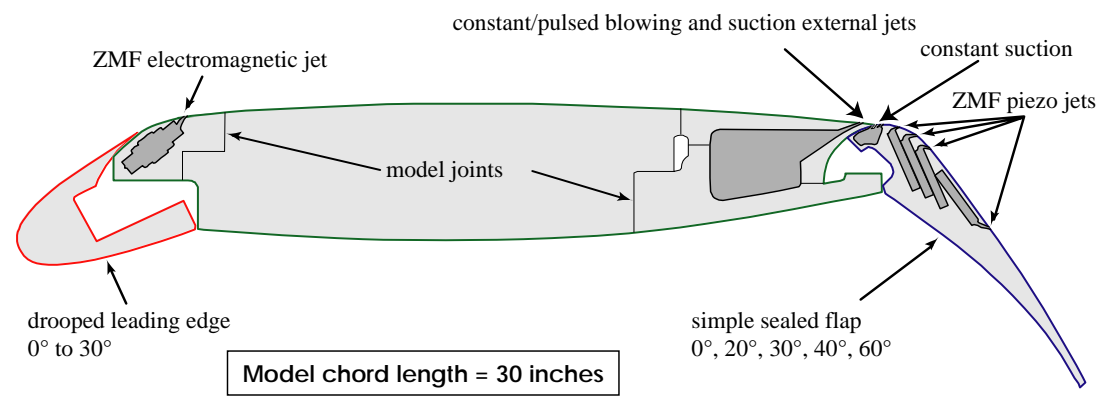

Figure 1. The EET airfoil with drooped leading edge and a simple hinged flap was designed and built by NASA to assess active flow control concepts.

For this study, the aft end of the configuration was modified to accept a new spoiler and a single-segment $0.28 c$-long slotted flap configuration, shown in Figure 2. The flap assembly was designed and built with provision to allow both 40 - and 50-degree deflections, with three gap settings of $\% 1 c, \% 2 c$ and $\% 3 c$ between the flap and the main-wing trailing edge. The available entry time in the LTPT allowed investigations at the 40-degree flap setting with the middle gap setting, with the $0.15 c$-long leading edge drooped at 30 degrees. Also shown in the same Figure is a table of max suction / blowing coefficients as well as frequency parameters for the actuators based on the expected peak slot velocities, slot height and actuator capability. 


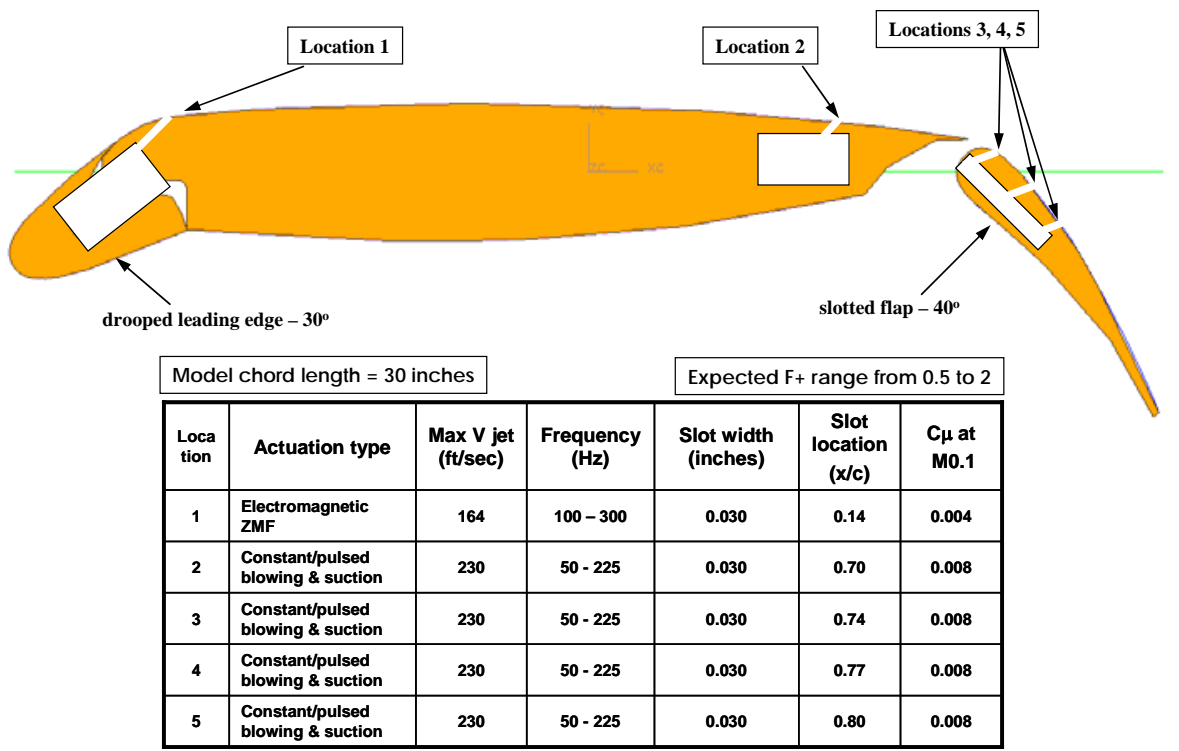

Figure 2. The NASA EET airfoil was modified to accept a single-segment slotted flap.

The predicted pressure distributions from a computational evaluation of the high lift configuration were used to guide placement of AFC slots on the main wing trailing edge and the slotted flap. The model leading edge, and the AFC slot in the model leading edge, was not altered from its original configuration designed by NASA.

Based on the predicted pressure distributions, and model design constraints, one slot location on the main wing trailing edge at $\mathrm{x} / \mathrm{c}=0.70$ and three slot locations for the flap were identified at $\mathrm{x} / \mathrm{c}=0.74,0.77$ and 0.80 in the stowed configuration coordinate system. The slot on the main wing trailing edge was fabricated in similar fashion. All slots were oriented at 30 degrees relative to the local surface slope, with opening of 0.030 inches.

The EET wind tunnel model is instrumented with 140 surface pressure taps in the chordwise direction. The highest density of the pressure ports is concentrated in the vicinity of the leading edge of the wing as well as the flap, where large changes in the pressure distribution were predicted to occur. All chordwise ports are at or near the model centerline. The lift values reported in this document were obtained by integration of the measured chordwise pressures.

The EET high-lift model is also equipped with 36 spanwise pressure ports distributed into three rows. The main purpose of this instrumentation was to monitor the health of the two-dimensional flow during testing. The wind-tunnel sidewalls can affect the two-dimensional flow, especially at high angles of attack. The tunnel sidewall boundary-layer control system is designed to alleviate the tunnel wall impact. The suction level for the sidewall boundary-layer control (BLC) system is set with the model pitched to an angle of attack of $14^{\circ}$. This suction level is then held constant during a complete pitch polar.

AFC Actuators - For steady actuation, the model internal cavities were connected to a custom-designed piping network. There were a total of four legs in the network, spoiler blowing, spoiler suction, flap blowing, and flap suction. Each leg contained a calibrated flowmeter, with associated pressure transducer and thermocouple, to directly measure the mass flow rate. The flow in each leg was controlled by a pressure regulator, which used an externally-generated control pressure to set the regulator opening. The control pressure was generated outside of the tunnel shell by a current-controlled pressure regulator, with the command current being generated by an I/O board in one of the computers used for the experiment. Compressed air for the blowing system was provided by a 300 psi supply line in the tunnel shell and suction was accomplished by controlled venting through the tunnel shell to atmospheric pressure. Selection of the blowing or suction mode was handled by two three-way valves, one for the flap and one for the spoiler. This allowed blowing or suction to be independently set on the flap and spoiler.

The wing leading edge housed up to six internally mounted ZMF actuators. The leading edge can house up to six internally-mounted electromagnetic ZMF actuators. The actuator is a variant of the "self-venting" 
design developed for US Army/Boeing Small Scale Active Rotor program. A total of four actuators were eventually used in order to provide passive pressure equalization under high tunnel total pressures associated with high-RN testing. This was done because active pressure equalization could not be implemented due to physical space constraints in the LTPT (insufficient sidewall clearance for pressure equalization tubing).

The ZMF actuation on the main wing and on the flap was provided by a pair of actuators fabricated by Nagib and Associates. These actuators (four total), one placed on each side of the spoiler and the flap, were too large to house internally. They were connected to the model internal cavities through specially designed routings which connected the actuator output to the model cavity. Details of the model instrumentation can be found in Reference 12.

Wind Tunnel - The Langley Low-Turbulence Pressure Tunnel (LTPT) is a single-return, closed-circuit wind tunnel that can be operated at stagnation pressures from 0.1 to 10 atmospheres. The test section is rectangular (3-ft wide by 7.5-ft high by 7.5-ft long) with a contraction ratio of 17.6:1. The chord length for a typical two-dimensional (2-D) airfoil test in the facility is approximately $2 \mathrm{ft}$. The turbulence levels of the LTPT are very low due to the large contraction ratio and fine-mesh anti-turbulence screens.

For two-dimensional single or multi-element airfoil tests, the model is mounted by endplates to a unique model-support and three-component force-balance system. Additionally, aerodynamic forces and moments are computed through the integration of the measured surface pressure distribution over the model. The facility is equipped with an electronically scanned pressure (ESP) system, which provides highly accurate steady-state surface pressure measurements of the model and the facility.

A 350-psi off site air supply system provides dry compressed air to the facility. On site storage tanks are utilized with an air capacity of $8000 \mathrm{ft}^{3}$ at 300 psi. The heat exchanger upstream of the anti-turbulence screens can be used either for cooling or heating the tunnel airflow.

LTPT's capabilities for multielement airfoil tests at flight Mach and Reynolds numbers are unique in the United States. The Mach-Reynolds number capability of the tunnel, as well as the tunnel schematic, showing the location of the two-dimensional test section relative to the tunnel circuit, is shown in Figure 3. Majority of the test was conducted at $\mathrm{M}=0.1$ and $\mathrm{RN}=3.6$ million per foot, which required tunnel circuit pressurization to approximately 5 atmospheres.

LTPT is equipped with hardware to provide sidewall boundary layer control (BLC) using either tangential blowing through tubes located on the model endplates or passive suction through porous endplates vented to the atmosphere. For this experiment the passive suction capability, patterned after earlier studies ${ }^{13,14}$ was used to maintain two-dimensional flow and to prevent the early onset of stall.

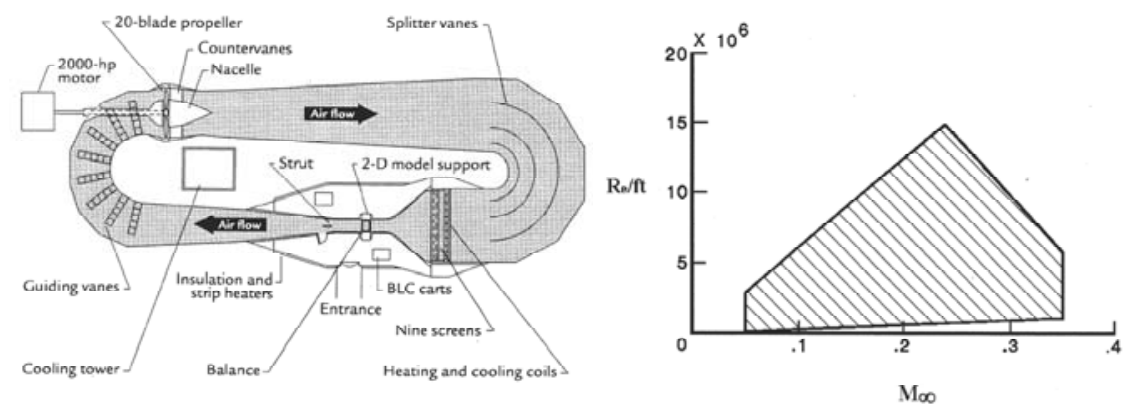

Figure 3. The LTPT wind tunnel layout and performance envelope.

The venting pattern utilized on the EET high-lift airfoil's upper surface is shown in Figure 4. The typical approach to setting the sidewall venting was to monitor the spanwise pressure port readings at 14 degrees airfoil incidence angle and set the sidewall suction level such that the spanwise pressure readings would be relatively uniform, and then maintain the same suction setting for the entire pitch polar. 


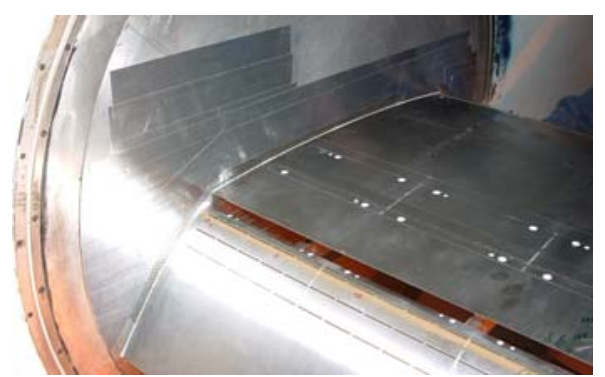

Figure 4. Sidewall-Boundary Layer Control is used to promote uniform flow on the model in the span-wise direction.

Example set of measured spanwise pressures is shown in Figure 5, where the measured pressure coefficients are shown from rows on the leading edge, main wing trailing edge and the flap - for three representative angles of attack. Also shown on the same plot is the location of the flap support brackets. Note the near-uniform pressures across the model span, on the leading edge and the main wing trailing edge. The flap enjoys the most uniform spanwise flow at the higher angles of attack, where it is required to be less responsive than at the lower angles of attack.

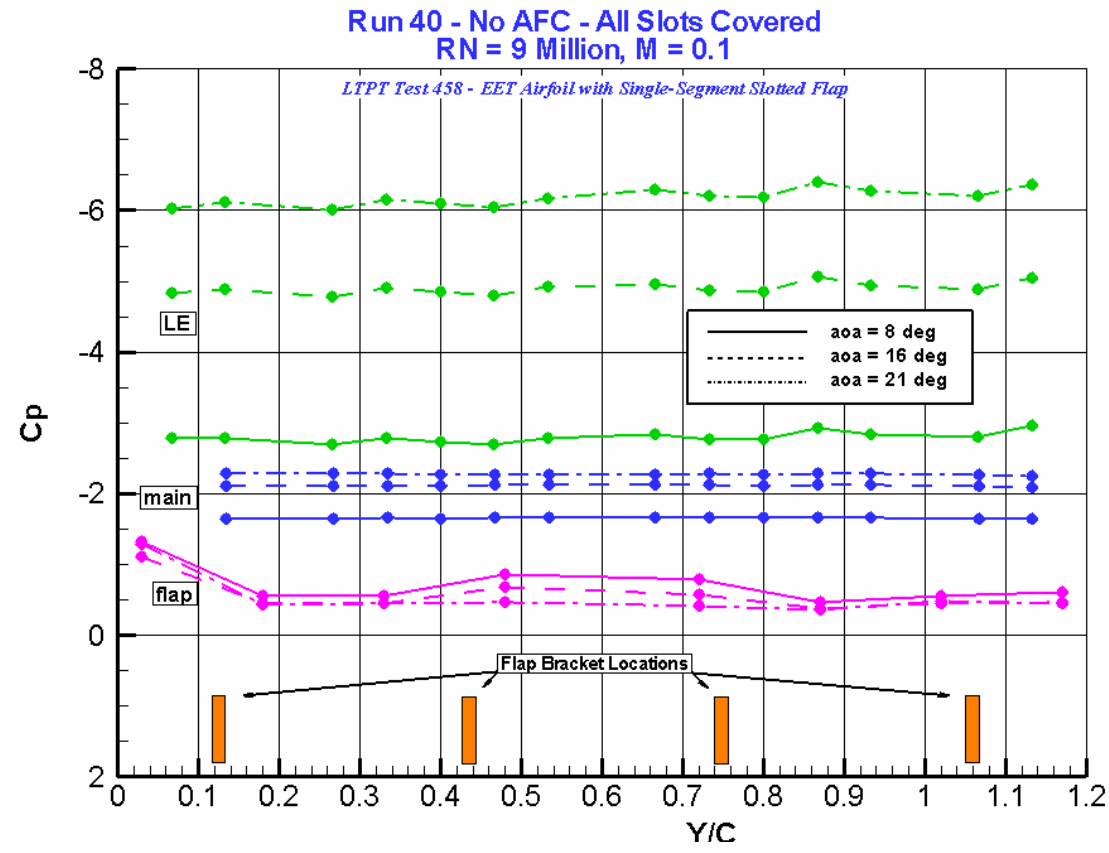

Figure 5. The measured span-wise surface pressures provide insight into the span-wise flow uniformity on the high-lift model elements.

\section{Calibration of AFC Actuators}

The AFC actuator calibration provides the relation between mass flow rates, voltage and frequency settings and suction / blowing velocities. The evaluation was carried out at various tunnel pressures in order to assess actuator performance under high atmospheric pressure conditions.

The process was carried out with a hot-wire anemometer after the wire was calibrated at select working plenum pressures (atmospheric, 25 psi, 50 psi, and 75 psi). The hot-wire signal was sampled at 12,800 samples/sec and a total of 30,000 samples were acquired per measurement. The hot wire apparatus was mounted at the AFC slot exit such that the hot wire tip was located adjacent to the slot exit, at the mid-span location of the AFC slot exit (tunnel centerline). Figure 6 shows the hot-wire apparatus and its location on the airfoil. Both mean and maximum velocity recorded during the sampling period were documented and reported. 


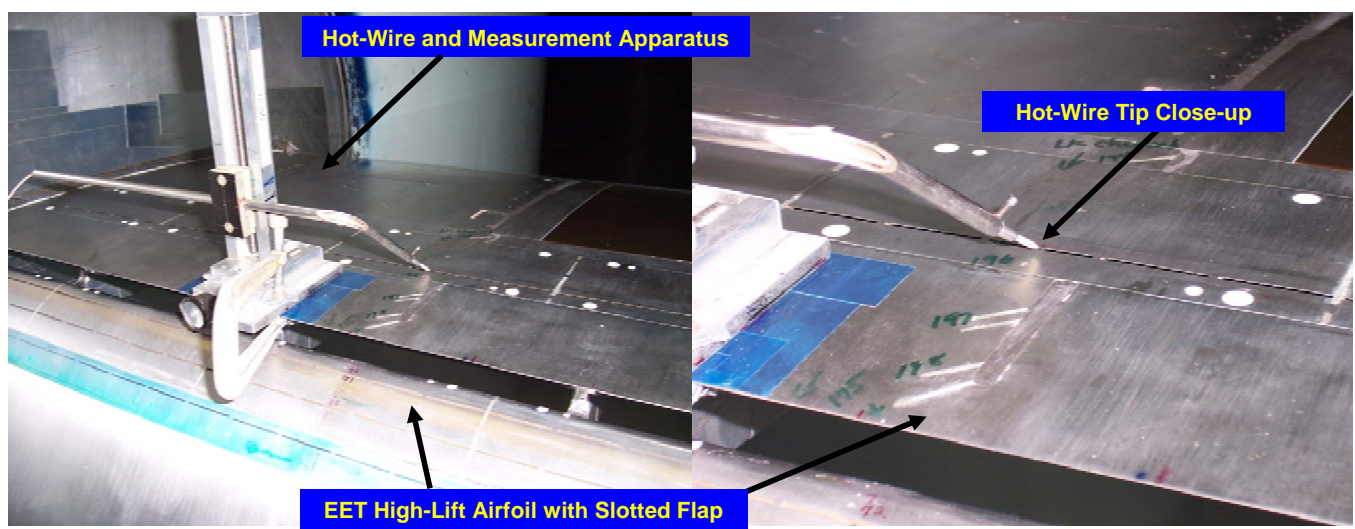

Figure 6. Hot-wire measurements were conducted at the AFC slot exits to calibrate AFC actuator performance.

The calibration results for the leading edge actuator are shown in Figure 7. The leading edge actuator was operated at excitation voltage of 30 Volts and frequency of 180 Hertz during the LTPT test of the EET high-lift airfoil (high-lighted by the dashed orange line on the plots). The calibration of the actuator posttest clearly shows that higher mean velocities could be obtained at lower frequency settings. The hot-wire measurements indicate that both the optimal actuator output (in terms of mean velocity at the AFC slot exit) and the frequency at which the optimal output occurs are inversely proportional to tunnel total pressure. This pattern appears to generally hold for the AFC actuators used on the aft end of the high-lift model as well. The calibration results for the actuators on the model aft end will be presently discussed.

Same pattern of behavior is observed in the measured peak velocities, also shown in the same figure. I.e. : measured levels of peak velocities, as well as the maximum levels of peak velocities both appear to be inversely proportional to the tunnel total pressure. The peak velocities, along with the mean velocities provide insight to the fluctuation level of velocity for the ZMF actuator.

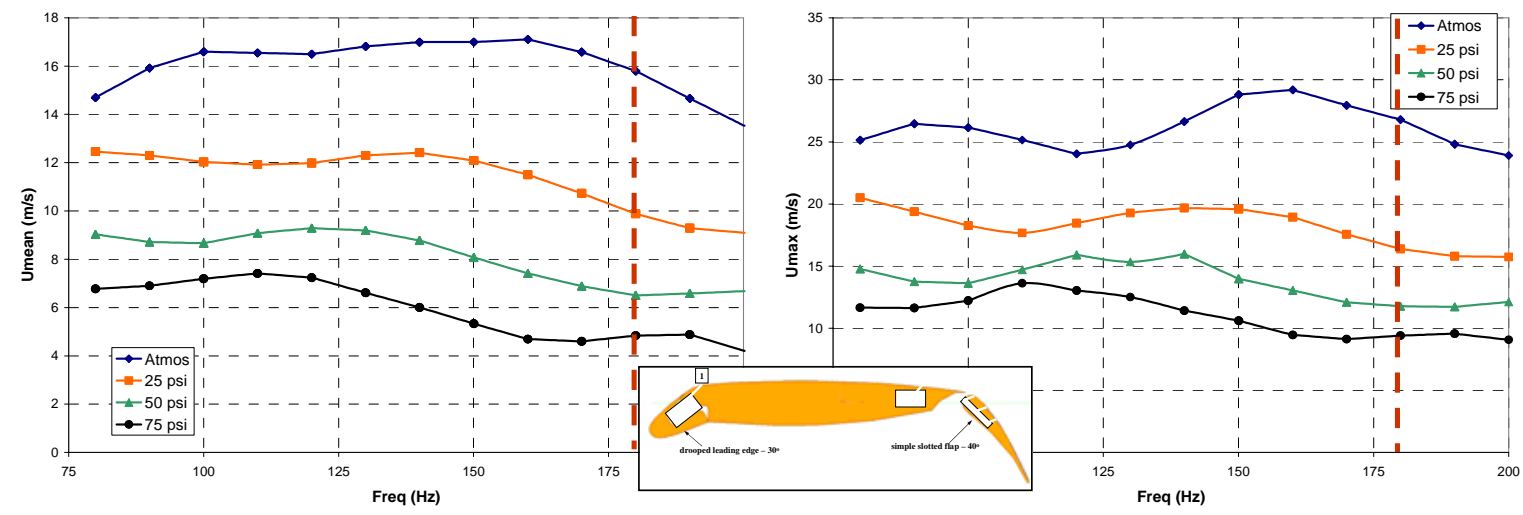

Figure 7. Mean and peak velocities (with 30-volt excitation) measured at the leading edge ZMF actuator slot exit, at the airfoil mid-span.

Velocity measurements were made for the Flap actuator running in ZMF mode at slot 3 with slots 4 and 5 taped shut. The mean and maximum velocity as a function of frequency for the different plenum pressures are presented in Figure 8. The AFC actuator systems in the flap and spoiler are made of similar components. Excitation voltage of 30 Volts was applied to each, with the spoiler AFC taking an excitation frequency of 160 Hertz and the lap AFC system taking an excitation frequency of 80 Hertz. These areas are high-lighted with the orange and blue dashed lines on the next few plots for reference. The observations noted for the leading edge ZMF actuator generally hold for the AFC actuator on the flap as well; namely, the actuator mean velocities as well as the peak velocities appear to be inversely proportional to the tunnel total pressure. The peaks also appear to take place at lower excitation frequencies with increasing total pressure. The spoiler AFC actuator, although not tested, is expected to have similar 
performance. At the highest tunnel total pressure tested, a persistent "peak" in the maximum velocity was noted at the 160 -Hertz frequency.

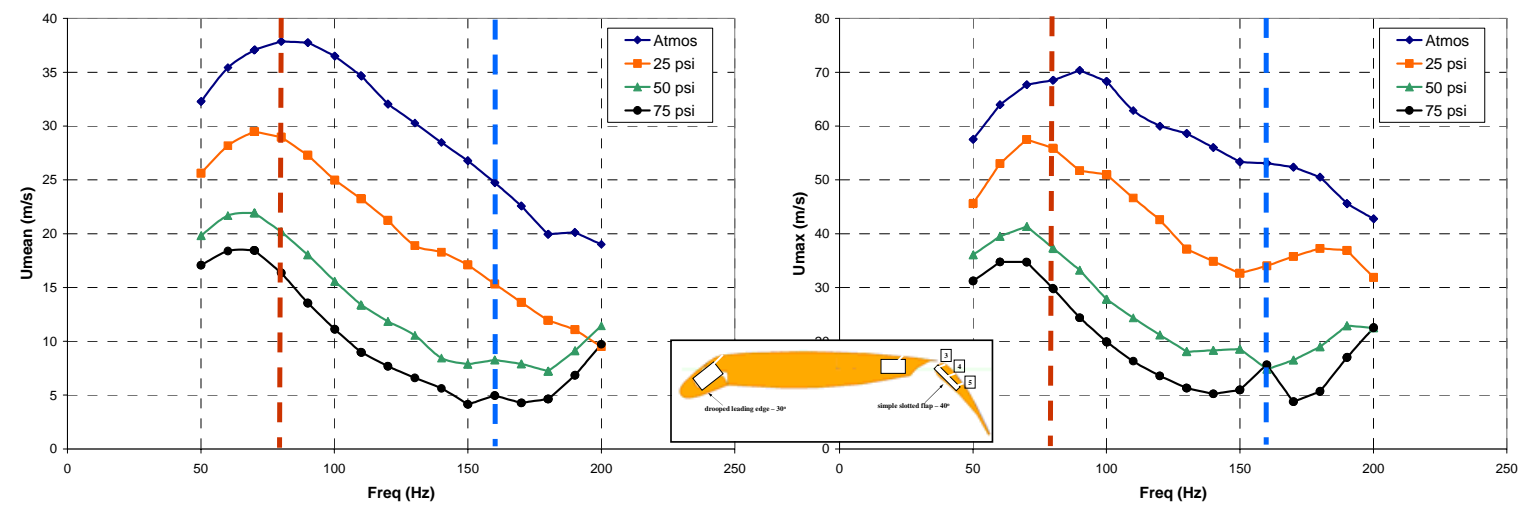

Figure 8. Mean and peak velocities (with 30-volt excitation) measured at the flap actuator (in ZMF mode) slot no. 3 exit, at the airfoil mid-span - slots 4 and 5 were taped shut.

AFC performance was also assessed on the flap with the middle slot (slot 4) open while the other two flap slots were taped shut. The mean and maximum velocity as a function of frequency for the various plenum pressures are presented in Figure 9.

The AFC performance pattern in this configuration appears very similar to the configuration were the forward lap slot (slot 3 ) is open and slot 4 and 5 on the flap are taped shut. The exception is in the velocity magnitudes - meaning that for a given tunnel total pressure and same excitation frequency, the measured velocities at the nozzle exit appear significantly lower when slot 4 is utilized as opposed to slot 3 on the flap.

The same persistent velocity "peak" noted in the configuration were slot 3 was active and slots 4 and 5 were taped is present in the results of testing for this configurations as well - especially at 75 psi tunnel total pressure and slightly notable at $50 \mathrm{psi}$ tunnel total pressure. The exact cause of this behavior is not known, although a possible reason (not examined in any detail during this calibration study due to time constraint) is the existence of a resonant frequency in the AFC chamber cavity. The repeatability of the mean velocity measurements is noted to be quite good over the range of actuator frequencies and tunnel total pressures tested.
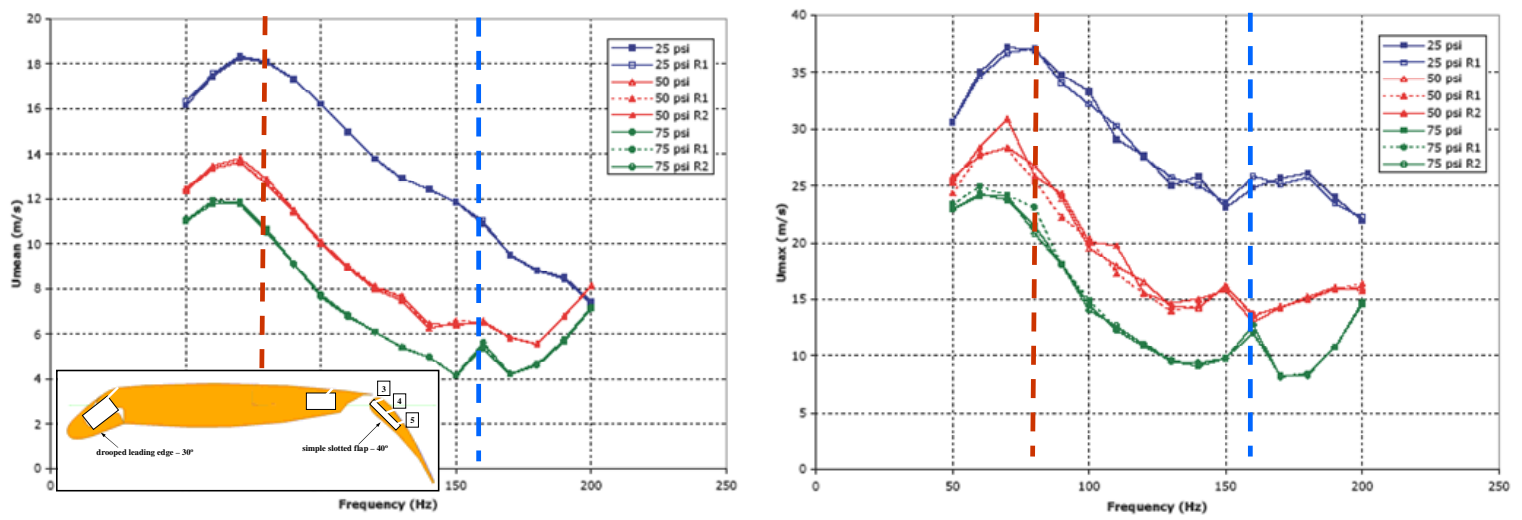

Figure 9. Mean and peak velocities (with 30-volt excitation) measured at the flap actuator (in ZMF mode) slot no. 4 exit, at the airfoil mid-span - slots 3 and 5 taped shut.

One of the configurations used during the testing of the EET high-lift model was usage of slot 4 on the flap without taping shut of slot 3 after the airfoil performance had been investigated in the configuration with slot 3 open. This was done in the interest of reducing tunnel down-time and model turn-around. Pressurizing and de-pressurizing the tunnel circuit can be quite considerable for conditions requiring high 
(flight-scale) Reynolds number conditions. The performance of the AFC actuation system on the flap was examined for this configuration. Exit velocities at slot 4 on the flap were measured while slot 3 was kept open and slot 5 remained taped and shut. Keeping the hot-wire at slot 4 and opening slot 3 and keeping slot 5 taped shut, the resulting mean and maximum velocity as a function of frequency for the different plenum pressures are presented in Figure 10.

Since the plenum mass flow is now exiting from two exits, the expectation is that the measured velocities at the slot exit should be lower than the configuration where only one slot exit is available for the mass flow to exit. The hot-wire measurements indicate velocities for this configuration are substantially lower than those measured for the configuration where only slot 4 was left open. Note that with slot 3 and 4 both open, the mass flow now has twice the area to exit compared to when only one slot is open. One would expect a 2:1 ratio for the measured velocity between the two configurations for the same actuator excitation level (voltage and frequency). The measured data clearly indicate that this is not the case, implying unequal distribution of mass flow between the two slots.
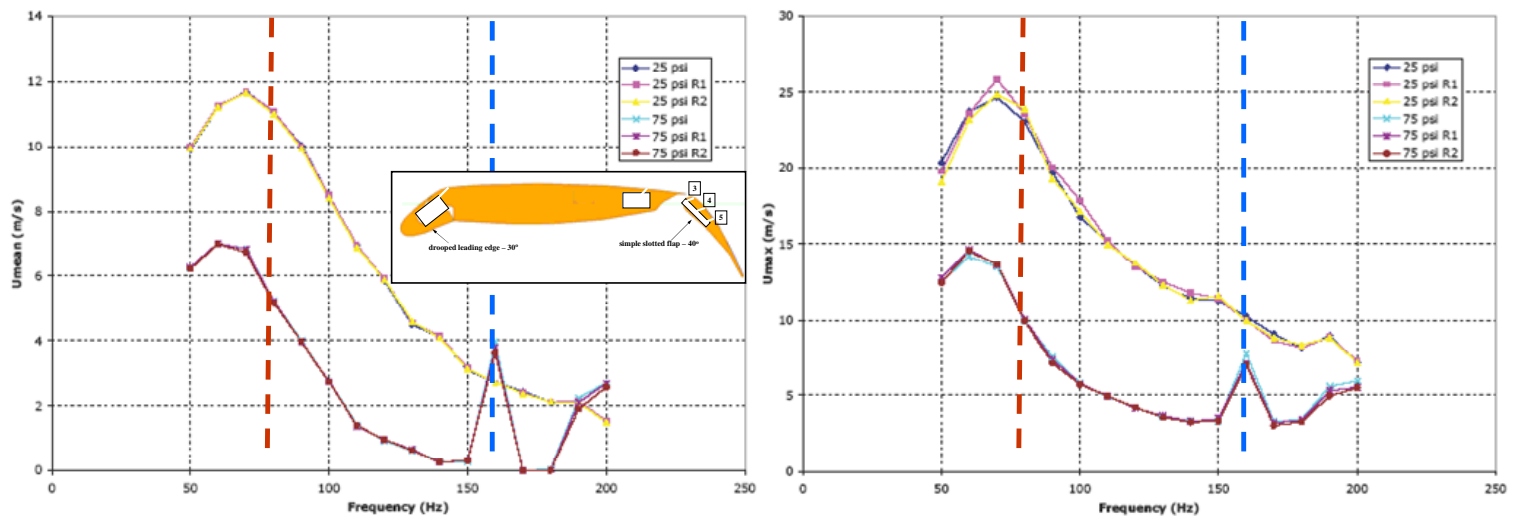

Figure 10. Mean and peak velocities (with 30-volt excitation) measured at the flap actuator (in ZMF mode) slot no. 4 exit, at the airfoil mid-span - slot 3 left open and slot 5 taped shut.

The small "peak" at 160 Hertz - observed in other flap measurements and described earlier - appears more pronounced in this configuration. Further analysis - perhaps correlation with the high dynamic response pressure transducers mounted inside the flap AFC cavity near the slot exit at the model centerline - could shed light on the nature of this persistent feature.

There are at least three observations that indicate presence of non-linearities within the AFC cavity on the flap:

1. With slots 3 and 4 are open, twice the exit area exists compared to when only slot 4 is open. Yet, the measured velocities for these configurations do not reflect a 2:1 ratio.

2. Measured velocities at slot 3 exit are substantially higher than those measured at slot 4 exit for a given tunnel total pressure. Both slots are plumbed to the same plenum, with slot 3 upstream of slot 4 by 3-percent stowed chord length.

3. The presence of a local small "peak" in the measured velocities for the tested configurations on the Flap has been reported to be persistent by the team making the measurements.

The perceived non-linearities warrant further assessment of the actuators' ZMF performance under high tunnel total pressures. The measurement results provided herein are the first of their kind. They have identified actuator performance that should be further investigated in order to fully document and understand ZMF actuator performance under conditions representing high Reynolds numbers in the LTPT.

The same AFC actuator on the flap was also evaluate when operating in the steady mode. Only steady suction velocity measurements were made for the flap at slot 4 with slot 3 and 5 taped shut. The results should be useful for evaluation of majority of steady AFC cases tested during the EET high-lift model test: only three cases were for steady blowing, and the remainder of steady AFC cases were in the suction mode, 
either on the spoiler or the flap. The measurements are presented in Figure 11. The solid lines without symbols are the theoretical velocity is expected for the given mass-flow and slot size. The lines identified as Flow Meter in this plot are the velocity measurements derived from the calculation procedure used during the testing of the EET high-lift model. This calculation procedure utilizes the mass-flow measurements from the turbine flow-meters and assumes uniform flow out of the slot in the spanwise direction, a uniform slot exit velocity profile and an isentropic expansion from the actuator plenum pressure to the tunnel static pressure for both the blowing and the suction operation. Since the hot-wire velocity measurements are higher than the calculated flow-meter velocities, the hot-wire measurements represent the peak of the exit velocity profile. It was very difficult to hold the control valve position steady at such low flow rates, and the hot-wire showed a higher degree of sensitivity to this than the turbine flow-meters.

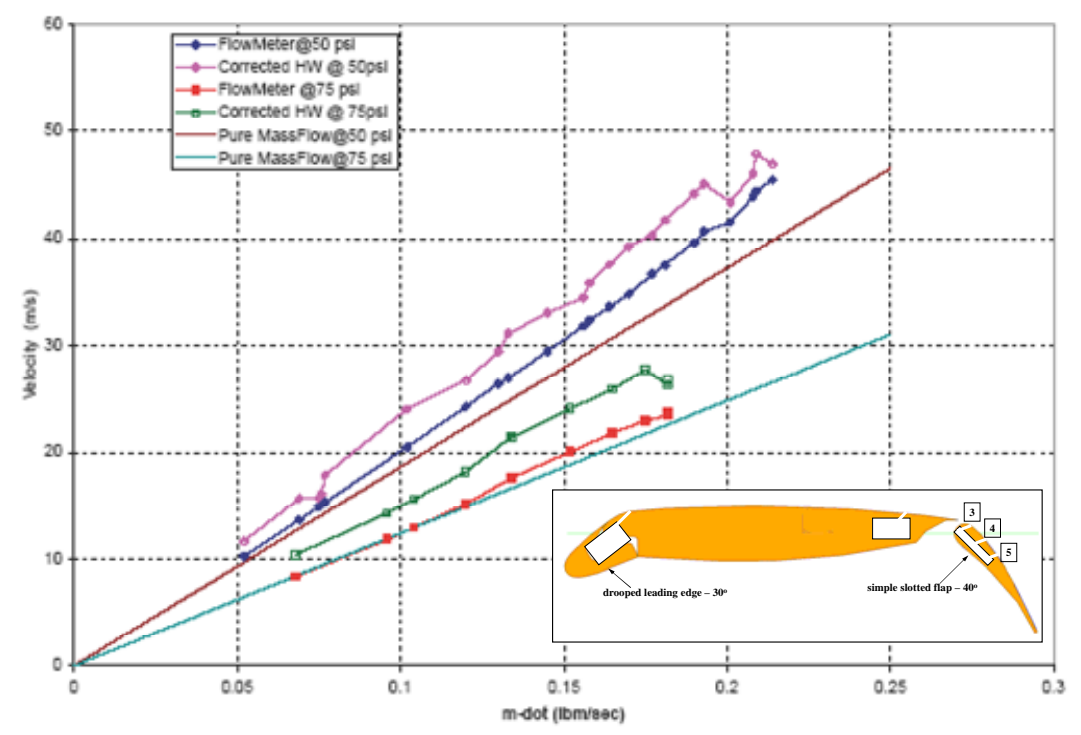

\section{Figure 11. Peak velocities (with 30 -volt excitation) measured at the flap actuator (in steady suction mode) slot no. 4 exit, at the airfoil mid-span - slots 3 and 5 taped shut.}

Mass flow rates used during the testing of the EET high-lift model in the LTPT ranged from 0.25 to 0.85 $\mathrm{lbm} / \mathrm{sec}$ on the main wing trailing edge (spoiler) and from 0.09 to $0.35 \mathrm{lbm} / \mathrm{sec}$ on the Flap when only slot 3 was open and from 0.2 to $0.55 \mathrm{lbm} / \mathrm{sec}$ when both slots 3 and 4 were used. Calibration data shown in this section indicate slot exit velocities with steady AFC in suction mode exceeded those obtained with ZMF operation at the same slot location.

The calibration data, although limited and in the case of the steady suction where not close to the range used during the high-lift airfoil testing, can provide insight to the AFC actuator performance and the exit velocities at the actuator exit. The measurements also point out that the actuators do not respond in linear fashion to increasing excitation levels. Velocity measurements at slot 4 on the Flap with slot 3 open and also with slot 3 shut can be used for guidance on implementation of suction/blowing coefficient levels when multiple slots are used on the flap.

\section{Description of Results}

A significant volume of flow control results will be evaluated in the following sections. The comparisons will sometimes involve evaluation of experimentally-measured lift performance for a variety of AFC settings, all on the same plot. All steady AFC data for will be displayed with solid lines while the ZMF AFC results will be shown with dashed lines. Steady suction will be displayed in blue, while steady blowing will be in red. The ZMF AFC data will be displayed in green. This format will be carried throughout the remainder of the comparisons to facilitate evaluation of the large sets of data. 
Baseline Measurements - AFC Off: Repeatability - The aerodynamic performance of the EET high-lift airfoil was evaluated first without the application of AFC in order to establish a baseline for the airfoil performance. Results of these measurements for lift are shown in Figure 12.

The baseline model's lift performance was influenced by the AFC slots being covered with tape. Once the tape was applied, Cyanoacrylate (CA) was applied to the tape leading edges and then lightly sanded to fair over the leading edge step. The measurement results shown in Figure 12 are for the baseline configuration with the five AFC slots on the model either all covered or some left uncovered. The reason for leaving some of the AFC slots uncovered was the substantial savings in time that otherwise would be needed to depressurize the tunnel for gaining access to the model and adjusting slot coverage as needed.

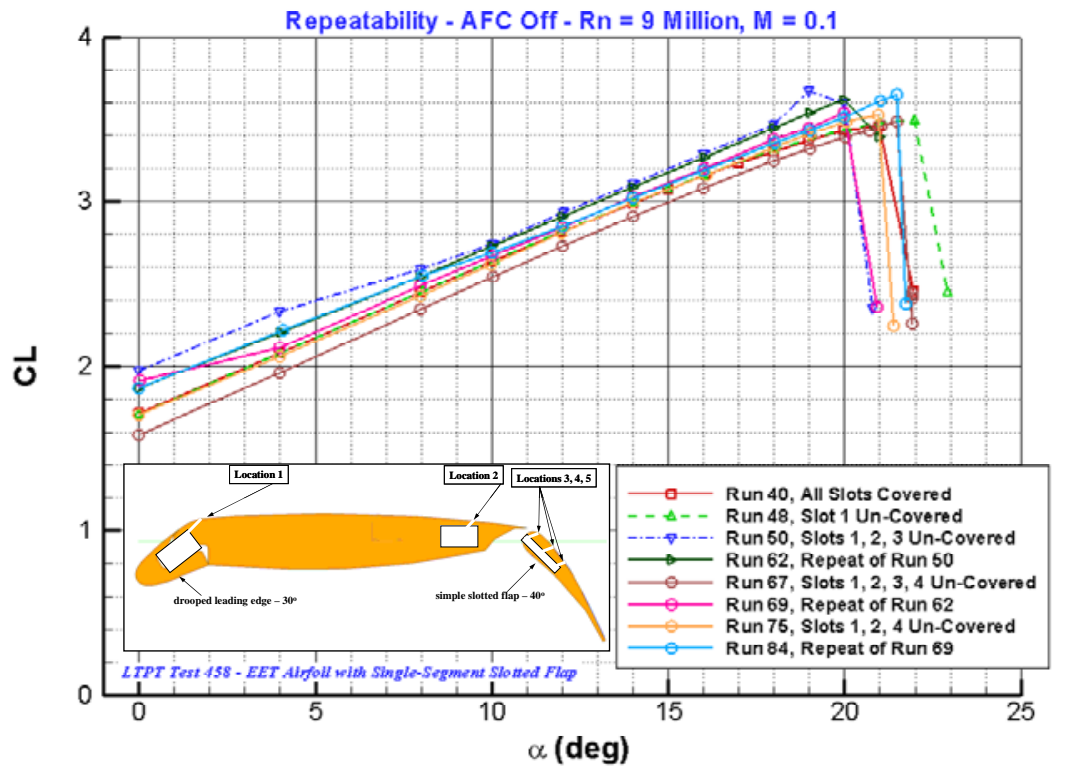

Figure 12. Baseline lift performance of the EET high-lift airfoil was sensitive to the placement of tape covering the AFC slots.

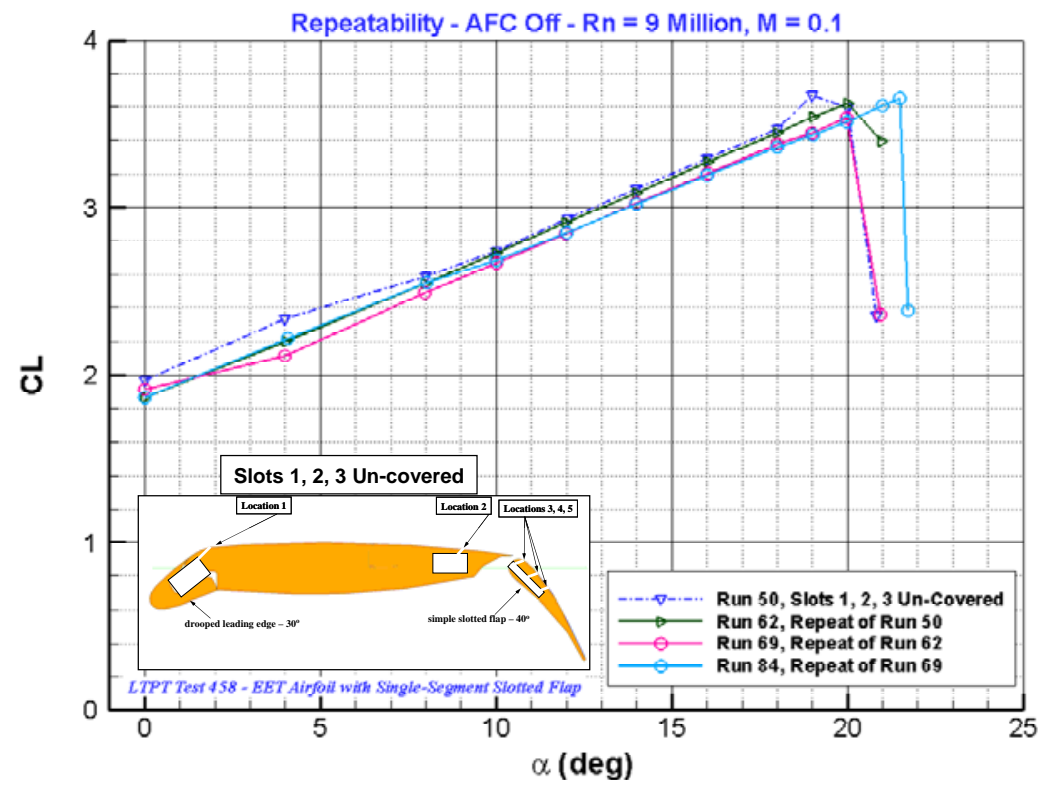

Figure 13. Baseline lift performance of the EET high-lift airfoil with AFC slots 1,2 and 3 uncovered. 
Figure 13 shows the repeat runs when only slots 1, 2, and 3 were left uncovered with tape. This was the mode of operation for most of the test, except when slot 4 was also needed.

Once all slots were covered, the repeatability of the baseline lift performance was excellent up to stall. The comparison shown in Figure 14 is for the baseline with all slots covered to a baseline case where only the leading edge slot (slot 1 ) was left uncovered.

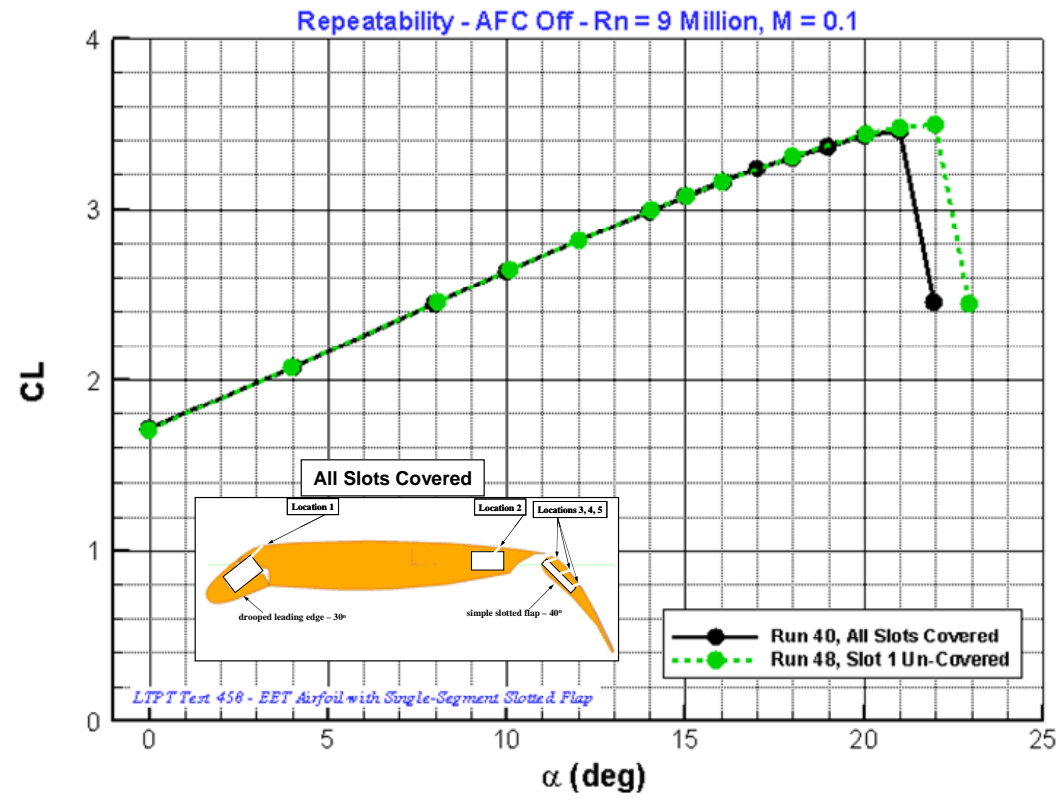

Figure 14. The Baseline lift performance of the EET high-lift airfoil repeats well when all AFC slots are covered.

There are three plausible reasons for the variations observed in the lift performance shown in Figure 12 and Figure 13 :

(1) Human variability in the application of tape to cover the slots - No specific notes were taken during the test to document the application of tape for covering the AFC slots. The tape - manufactured by Airtech with the brand name "Flashbreaker 2" - has a thickness of 0.0020 inches. The tape may not have replaced in the same chordwise location.

(2) Presence of some outflow through the un-covered slots - due to the lower static pressure brought on by the free-stream airflow on the model surface. The flap cavity pressure transducer could provide insight; unfortunately the cable for this transducer was sheared during installation, so the dynamic pressure transducer data is not available to investigate this possibility.

(3) Presence of a resonant frequency inside the AFC plenum cavity - Assessment of the highfrequency pressure measurements inside the AFC cavities can shed further light on the source of variations in the repeat runs. The flap cavity instrumentation cable was sheared during installation (as pointed out in 2 above) and therefore no measurements were recorded from this instrument. However, flow visualization conducted after the test indicated a very low frequency separation and reattachment occurring with slot \#3 open - potentially due to a resonance in the cavity.

None of the possibilities discussed here were examined to a great extent during the testing period in the LTPT due to limited time constraints. They will have to be sorted through if a future test entry under similar conditions is planned.

The effect of taping the AFC slot can also be observed in the model pressure distributions. Whether the tape coverage was affecting the measurements was not studied systematically in the LTPT test, but there is enough evidence that warrant coverage of non-operating AFC slots during future entries. Figure 15 shows the pressure distribution on the airfoil for a configuration where all slots were covered with tape (Run 040), and configurations where various slots are left un-covered. The results shown are for a condition well 
below stall. Pressure measurements on the flap indicate that flow remains attached on the flap downstream of the peak pressure coefficient, so long as slot 3 is covered. With slots 3 un-covered, a sharp rise in the peak pressure coefficient is noted (Run 67) on the flap, followed by flow separation. It appears that leaving slot 3 un-covered makes a great impact on the distributed loads generated on the airfoil.

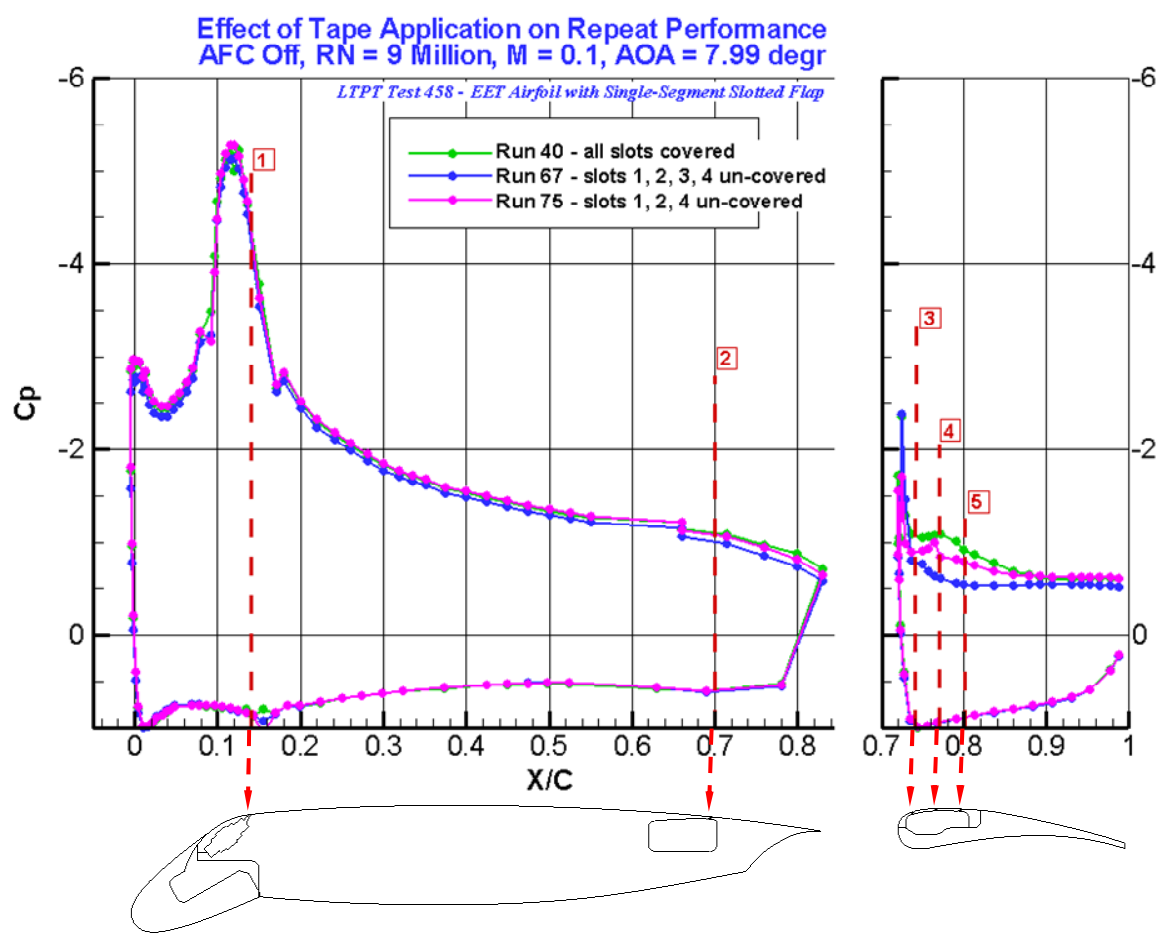

Figure 15. Application of tape impacted the distributed pressures.

The data shown in Figure 12 and Figure 13 depict the variability in baseline performance when slots 1 through 4 were left uncovered. While the measurement from Run 40 (shown in Figure 14) will be used as baseline performance, majority of the AFC runs were carried out in the configuration shown in Figure 13 (slots 1, 2, 3 uncovered). Based on the limited set of repeat runs on the baseline configuration, the repeatability of lift coefficient is noted to be within \pm 0.05 for most of the pre-stall and within \pm 0.08 at maximum lift performance for these cases.

A lesson learned during this test entry was that the uncovered AFC slots can contaminate the measurements. In future testing in similar conditions, more thought should be given to the value of data accuracy in lieu of time saved by reducing tunnel stoppage time for application and removal of tape to cover AFC slots. The repeatability of the lift performance can be improved considerably during future testing with the same model if the unused AFC slots are covered. For evaluation of results from this test, however, there is little choice but to accept the level of repeatability based on the limited repeat measurements shown in Figure 13.

The chordwise surface pressure measurements provide a good indication of where flow separation occurs on the model. The measured pressures on the model are shown in Figure 16 for Run 040 at several angles of attack. Note that at angles of attack prior to stall, the measured pressures on the flap indicate separated flow on most of the flap upper surface, consistent with prior observations on high-lift configurations equipped with a single-segment flap at aggressive flap deflections.

The results shown in Figure 16 also indicate that the flap's lift performance decreases with increasing angle of attack, up to stall. This trend is also consistent with our understanding of slotted flap lift performance, where the interaction of pressure forces (also known as circulation on the main wing and flap) cause the flap to "unload" with increasing angle of attack. Once stall is reached, and the main wing has lost its ability to generate lift (or circulation), increase in flap performance is observed. 


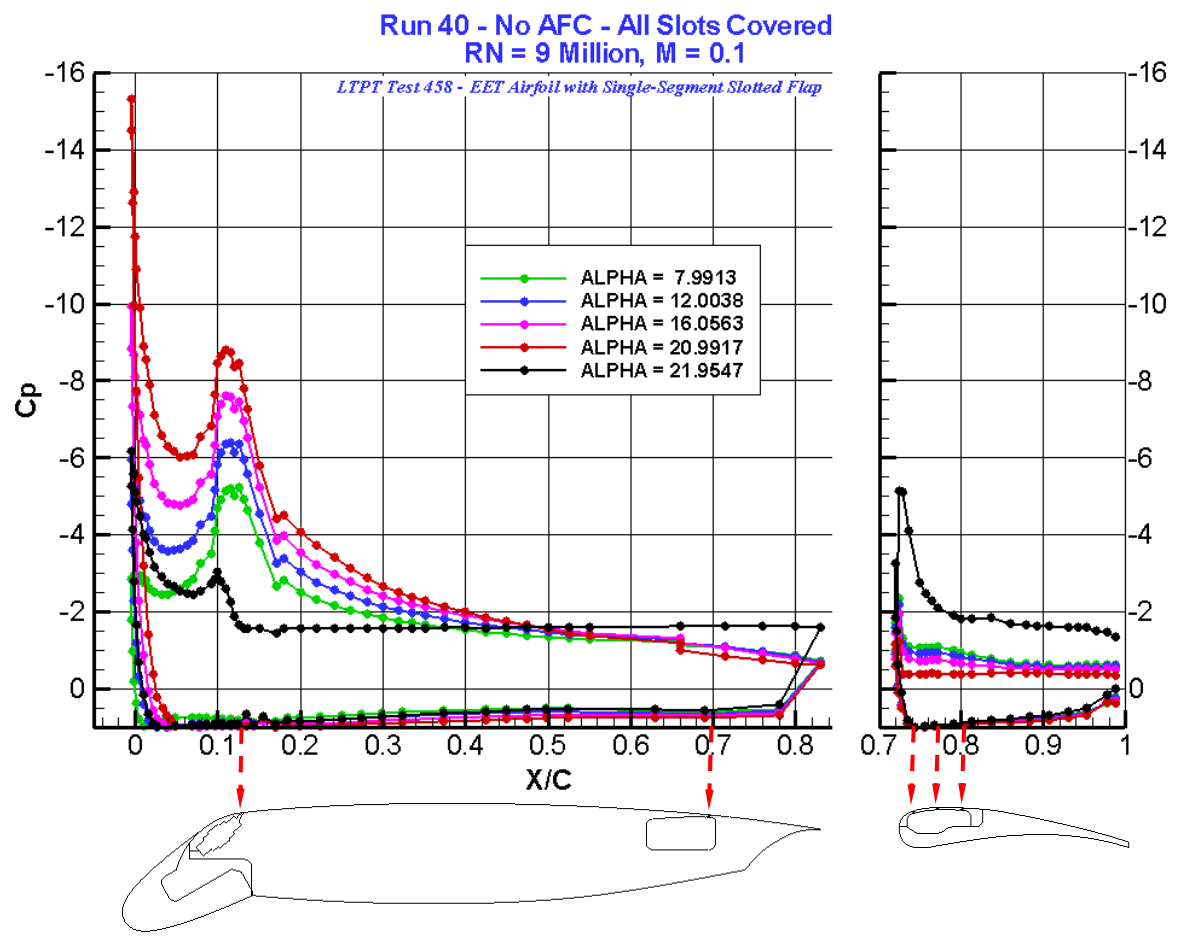

Figure 16. Measured surface pressures provide insight into the performance of individual high-lift model elements.

Baseline Measurements - AFC Off: Reynolds Number \& Mach Number Effects - The airfoil's baseline lift performance sensitivity to variations in Reynolds and Mach number were investigated. These results are shown in Figure 17.

Typically, the aerodynamic performance of high-lift system employing a slotted flap varies with the variation of Reynolds number. This is a compelling reason for undertaking a complex wind tunnel measurement that allows simulation of flight-scale conditions. The results shown in Figure 17 suggest that lift performance increments obtained at conditions far below flight scale would lead to erroneous design considerations. The airfoil's lift performance sensitivity to Reynolds number variation was also investigated with AFC on - these results are discussed later in this paper.
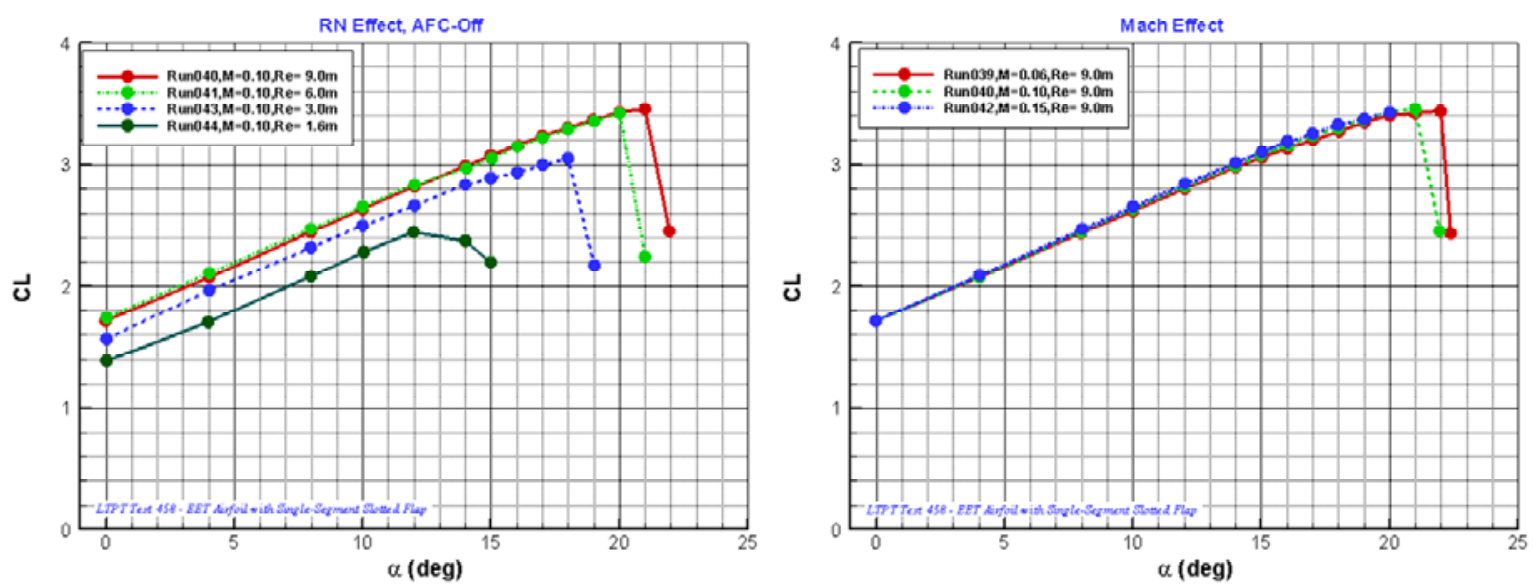

Figure 17. Measured baseline lift performance exhibits strong sensitivity to Reynolds number variation and little sensitivity to Mach number variation. 
The pressure distribution on the high-lift model can shed light on the large variation in the lift performance. Figure 18 shows the measured pressure coefficients for the four Reynolds numbers at 8 degrees angle of attack. Note that at the lowest Reynolds number (RN), the flow over the flap is completely separated. The measured pressures on the flap indicate partially attached flow with increasing Reynolds number, with the largest change being noticeable at the lower range of the Reynolds numbers examined.

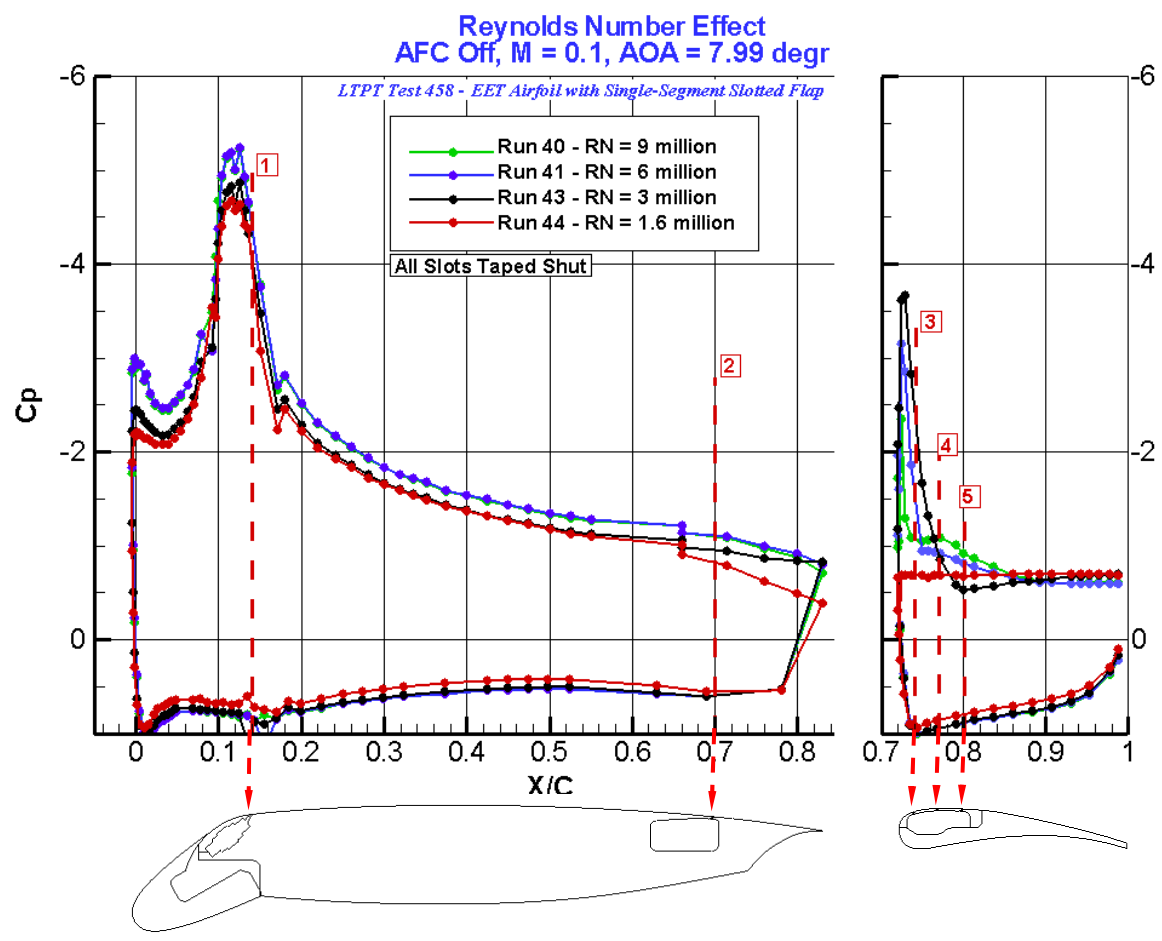

Figure 18. Pressure distribution on the EET high-lift model shows highly separated flow on the flap at low Reynolds numbers.

Sensitivity to Reynolds number variation of this magnitude has been observed in previous testing with other high lift systems. Reference 15 described the results of a wind tunnel test conducted in the LTPT using the EET airfoil, rigged in a high-lift configuration which is different from that used in the present test. Results shown in Reference 15 (Figures 29 - 47) indicate strong sensitivity of the EET high-lift airfoil lift performance for some of the conditions tested in that experiment.

In some cases, the large variation in lift performance can be attributed to a high lift system optimized to perform well in a particular Reynolds number regime. A high lift system optimized to perform well at Reynolds numbers associated with large transports, can perform poorly at sub-scale conditions with the opposite being equally possible for a configuration optimized to work well for small transports. The thickness and interaction of confluent boundary layers present in high lift systems can be strongly affected by Reynolds number variation. Further explanation of this phenomenon can be found in Reference 16 see Figures $5-8$ and associated discussion in that Reference.

The tested configuration exhibited little sensitivity to variations in Mach number, over the range of Mach conditions evaluated. Further assessment of the high-lift configuration would have been carried out to fully assess sensitivity to Mach number variation, had this airfoil been chosen for an actual vehicle development. This would be a critical step, at a minimum, for assessment of gust effects during approach and landing conditions.

Flow Control Results - Reynolds Number Effect and Repeatability - In the previous section, both repeatability and sensitivity of the airfoil performance to Reynolds number variation was examined. During the application of AFC, the effects were investigated again. The results are shown in Figure 19 and Figure 20. 
The back-to-back repeat data shown in Figure 19 exhibits the same behavior as that observed in the baseline result shown in Figure 14. The lift performance repeats very well up to stall, where a variation in both max lift level as well as stall angle is noted. Possible explanation for this difference in behavior can be attributed to the large model size and the sidewall suction system not providing adequate capability up to CL max conditions.

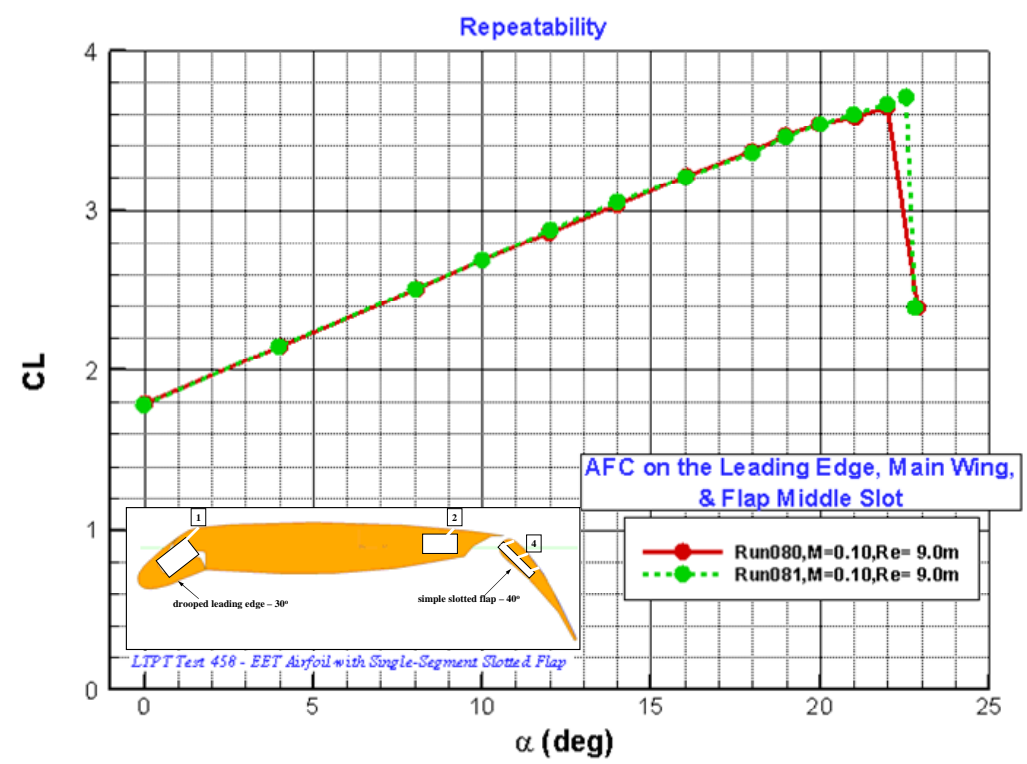

Figure 19. Lift performance of the EET high-lift airfoil repeats well with AFC on.

The sensitivity of the high-lift airfoil lift performance to Reynolds number variation was evaluated with AFC On. The results, shown in Figure 20, indicate the sensitivity can be quite strong, although more indepth analysis and a broader range of testing will be required to increase confidence levels. For these measurements, the AFC actuation was set at the first Reynolds number condition tested. Once the measurement was obtained, the Reynolds number was changed to the next setting, without applying any adjustments to the AFC actuation settings (amplitude or frequency). During the post-test AFC slot exit velocity calibration, the variation due to change in Reynolds number was examined. The results for the leading edge and for the flap (slot 3) actuators operating in the ZMF mode were shown in Figure 7 and Figure 8. The measurements indicate that the jet velocity at the exit is very sensitive to variation in Reynolds number. In spite of this inconsistency, the results of the measurements shown in this figure (and those from Figure 17) suggest that using performance data from conditions below flight-scale can be quite misleading.

The measured pressures for 8-degree angle of attack are shown in Figure 21. The general trend is similar to that observed for the baseline AFC-off case examined earlier. The Reynolds number sensitivity assessment was not carried out for all tested configurations due to limited test time. The configuration discussed here is representative and the results warrant careful selection of testing conditions in order to best represent flight-scale conditions for the aircraft configuration of interest. At the lowest Reynolds number (1.8 million), the measurements indicate flow over the flap upper surface to be separated. The measurements indicate that flow partially attaches to the flap upper surface when the Reynolds number is increased to 3.1 million. Maximum flow attachment on the flap occurs with increasing the Reynolds number to 9 million and marginally less at 6 million. The upper surface measurements on the main wing indicate the flow over the wing trailing edge to be highly affected by the flap's performance. With the flap working harder (increasing Reynolds number), the entire main wing is also affected, as observed from the pressure measurements on the main wing. This "pumping effect" where the flap performance "pumps" the main wing performance is a common occurrence in high-lift aerodynamics. 


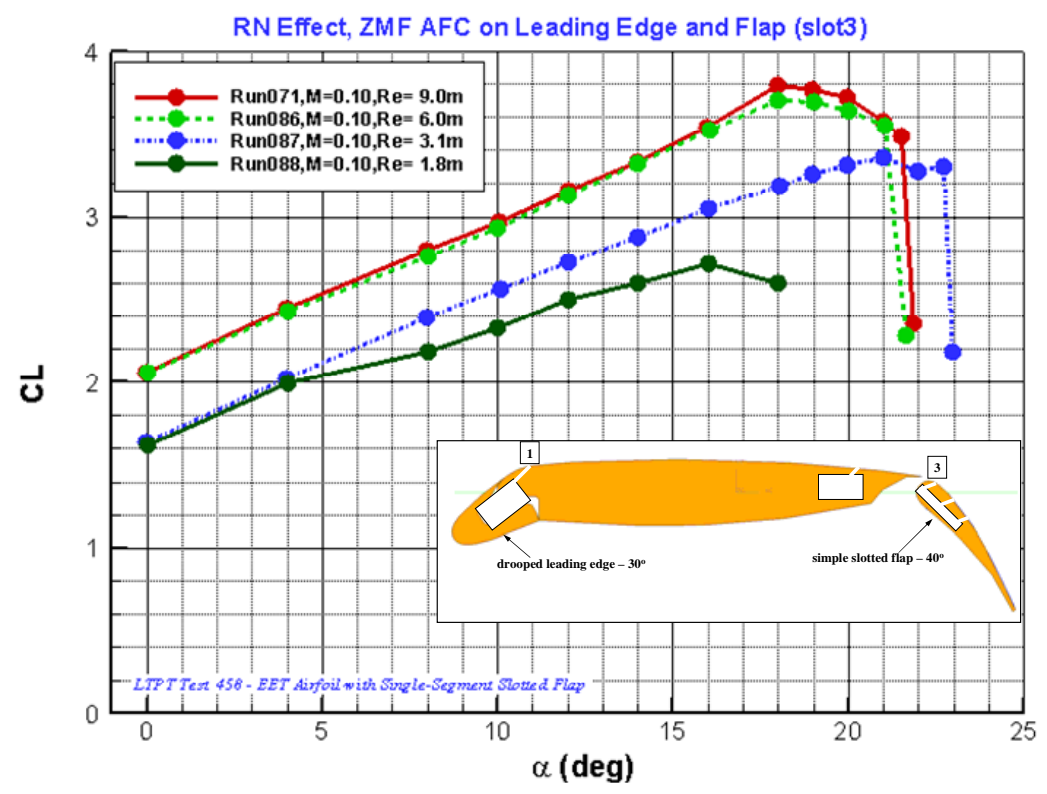

Figure 20. Measured lift performance with AFC on exhibits strong sensitivity to Reynolds number variation.

Two major differences are noted between the AFC Off and On cases shown in Figure 18 and Figure 21:

1. The "kink" noticed in the upper surface pressure distribution just upstream of slot 1 in the AFC Off case is not present when the leading edge actuator is operational.

2. The overall pressure coefficient levels for both the main wing and the flap are noticeably higher with the AFC On. The peak pressure coefficients on the main wing and flap were approximately -5.2 and 3.6 for the AFC Off condition, in contrast with -5.8 and -4.5 for the AFC On case shown in Figure 21.

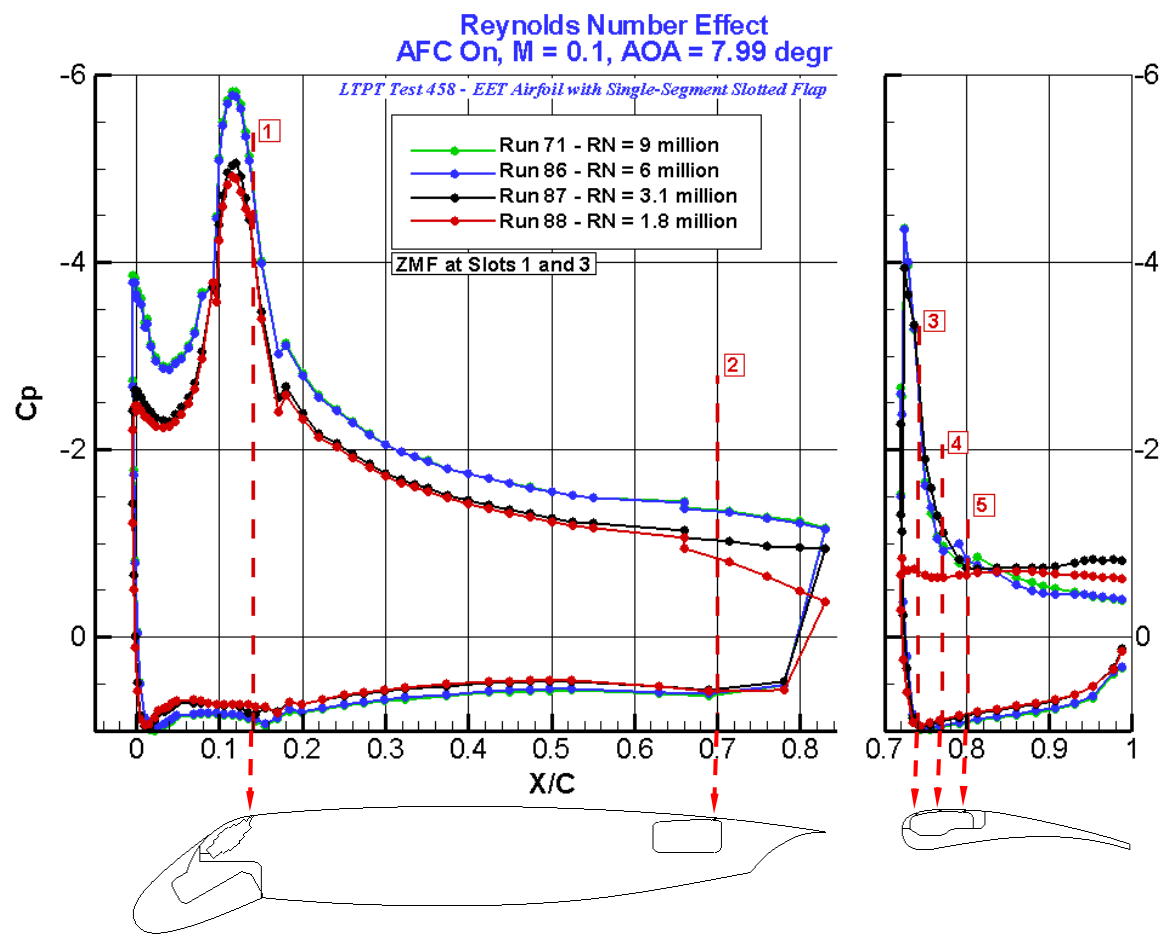

Figure 21. Measured pressure distribution with AFC on exhibits strong sensitivity to Reynolds number variation at the lower end of the evaluated RNs. 
Another way to examine the performance sensitivity to RN scaling is assessment of lift increments due to changes in RN, shown earlier in Figure 18 and Figure 21. The result of this analysis is shown in Figure 22 for conditions well below stall and at maximum lift. The lift increment shown in this Figure is defined as the difference relative to the lowest RN tested in this study. Similar lift increment is observed between the AFC-off and AFC-on measurements at maximum lift conditions. The increments, however, are noticeably different at conditions below stall. Several observations should be made:

1. The baseline lift curves (the lowest RN lift curve) for AFC on and AFC off cases show drastically different lift performance. Lift degradation beyond $\alpha=4^{\circ}$ is noted for the AFC-on condition and is likely the cause in the large difference in lift increment noted for higher angles of attack.

2. The state of the boundary is not known, particularly at the low RNs. The baseline AFC-off cases show some variation in lift increment up to $\mathrm{RN}=6$ million.

3. The lift performance of the EET with AFC off shows a monotonic increase in maximum lift and stall angle. The AFC-on data show a breakup in this behavior. Plausible reasons are

a. presence of wall effects that are not quite removed with the wall boundary layer removal system, and

b. breakdown of AFC actuator's ability to provide consistent output across the model span, as the airfoil performance reaches $C_{L} \max$ conditions.

4. During the course of changing the tunnel conditions for varying the RN, the actuator output settings were not changed. As a result, the exit jet velocity and $\mathrm{C}_{\mu}$ is not held constant with increasing RN (see Figure 7 through Figure 10).

Based on these observations, RN effects appear to be significant using the limited dataset obtained during this study. What is not clear is that whether the RN effect noted in the limited AFC-on cases examined, is drastically different from the baseline AFC-off conditions. Further testing with tight control of the AFC variables, over a wider range of high lift and AFC configurations will be needed to address this important issue.

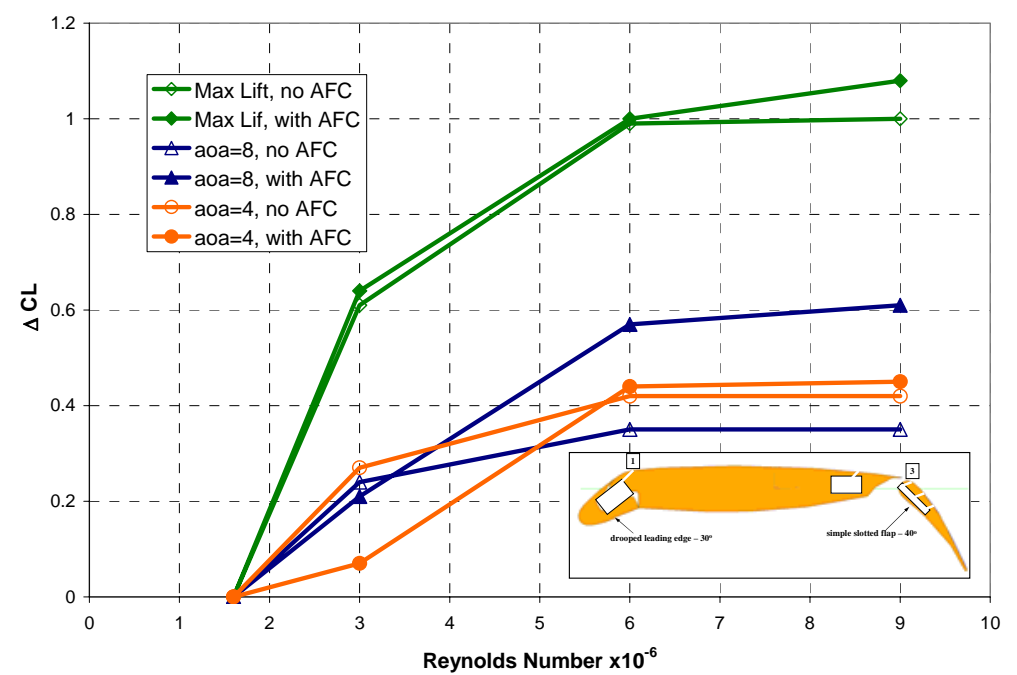

Figure 22. Changes in the lift increment with varying $R N$ are indicative that differences in $R N$ scaling may exist when AFC system is operational.

Flow Control Results - Leading Edge - Application of AFC on the leading edge was carried out through ZMF actuation devices. The limited size of the model leading edge precluded application of steady suction or blowing in this area. Results of application of ZMF AFC on the lift performance of the airfoil are shown in Figure 23.

Application of ZMF AFC on the leading edge alone caused a slight increase in lift performance. Changing the actuator excitation amplitude by one-half did little to affect the noted change in the lift performance. With all slots covered except for the leading edge slot (Run 49), application of AFC at the leading edge 
increased the airfoils maximum lift and stall angle, but did not change the lift curve slope. All the un-used AFC slots were taped shut during Run 49, so the measurements are not diluted with potential contamination due to outflow from open and un-used AFC slots.

Also shown on the same plot is the inviscid performance prediction. It provides a measure of the airfoil lift performance increment achieved with AFC relative to the predicted ideal inviscid performance level.

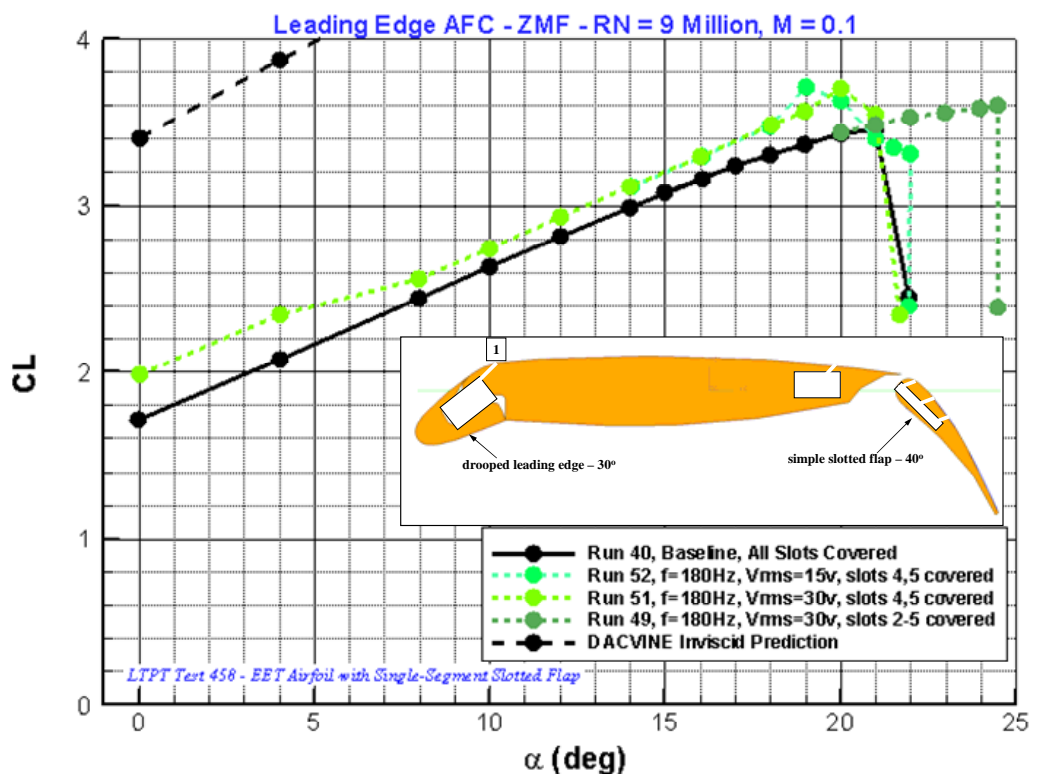

Figure 23. Lift performance of the EET high-lift configuration was little affected by the application of AFC on the leading edge.

Representative pressure distributions for this configuration are shown in Figure 24 for 22 degrees angle of attack. The measurements show that with all the slots taped shut except the leading edge slot where ZMF AFC is being applied (Run 49), application of AFC forces attached flow on the main wing even though the flap upper surface flow is fully separated, thus allowing improved stall margin as well as slight increase in maximum lift. Run 52 and Run 51 exhibit the same stall pressure distribution as the baseline case (Run 40). Contamination from un-covered leads us to conclude the results from those two runs are questionable.

Flow Control Results - Main Wing Trailing Edge - Application of AFC on the main wing trailing edge was carried out through both steady and ZMF actuation. Result of the measurements for steady suction and blowing as well as ZMF actuation on the main wing trailing edge are shown in Figure 25.

Overall, application of steady suction or blowing is noted to affect the airfoil's lift performance more noticeably than the application of ZMF flow control at the main wing trailing edge over the range of examined AFC conditions. Application of suction - in the smallest amount (Run 53) affected the lift performance in nearly the same manner as when the mass flow rate was more than tripled (Run 54), with the higher mass flow rate able to increase maximum lift and stall angle slightly more than the low mass flow rate.

Flow Control Results - Flap - Application of AFC on the flap was carried out through both steady and ZMF actuation. Flow separation on the flap can significantly affect the high-lift airfoil's performance. In order to provide some level of flexibility in terms of AFC location, three slots were placed on the flap upper surface. Result of the measurements for steady suction and blowing as well as ZMF actuation from the first slot on the flap are shown in Figure 26. 


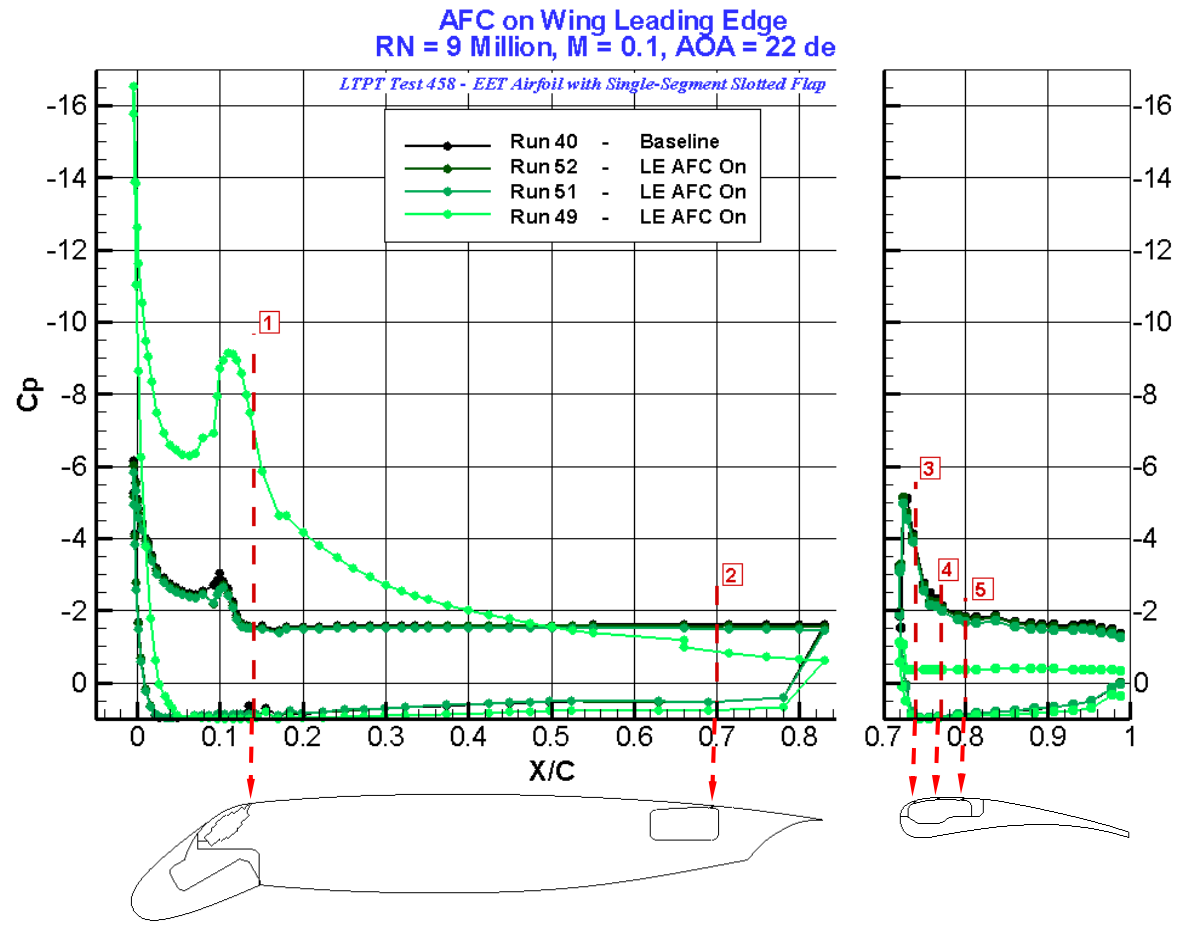

Figure 24. Lift performance of the EET high-lift configuration was little affected by the application of AFC on the leading edge.

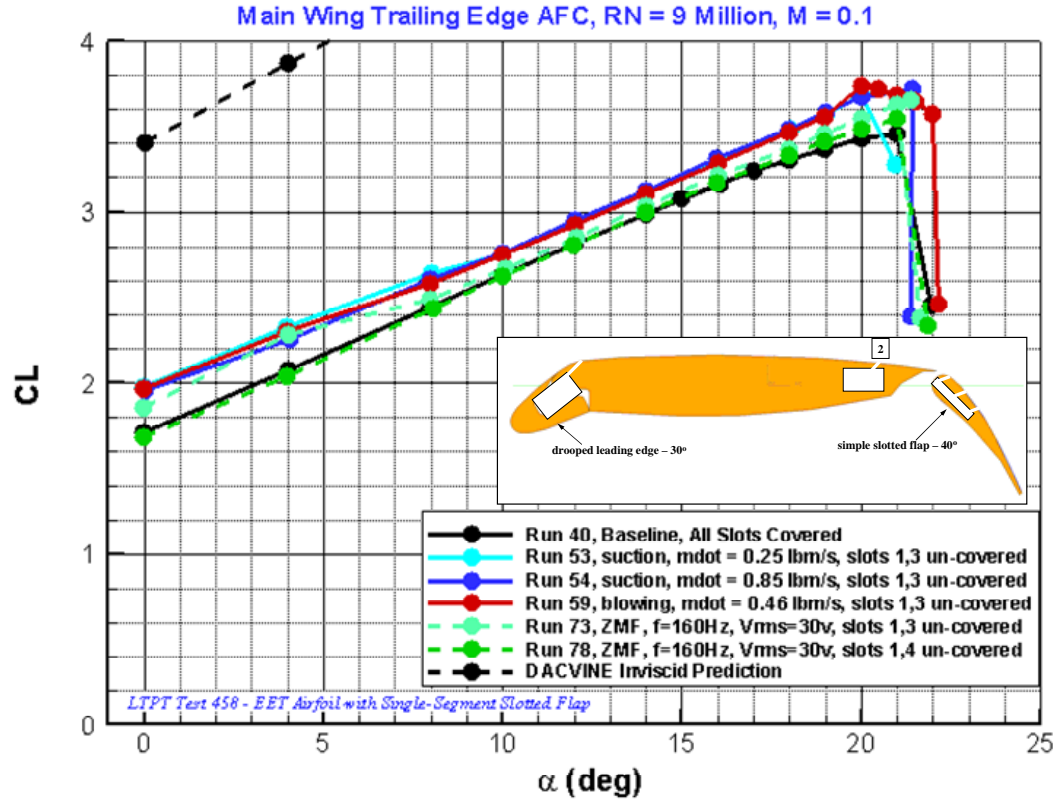

Figure 25. Lift performance of the EET high-lift configuration was little affected by the application of AFC on the main wing trailing edge.

Application of AFC on the flap resulted in the most drastic change in the airfoil performance, compared to application of AFC at the two forward locations on the airfoil. Application of even small amounts of steady suction (Run 56) caused a large increase in the airfoil's lift performance, while application of steady blowing produced nearly the same amount of lift increment as did the application of steady suction for the same mass flow rate (Run 55 and Run 58). Application of ZMF from the same slot on the airfoil produced 
the lowest lift increments among the conditions tested. Future comparisons can be more meaningful with a measure of the actuator power consumption to achieve the lift gains.

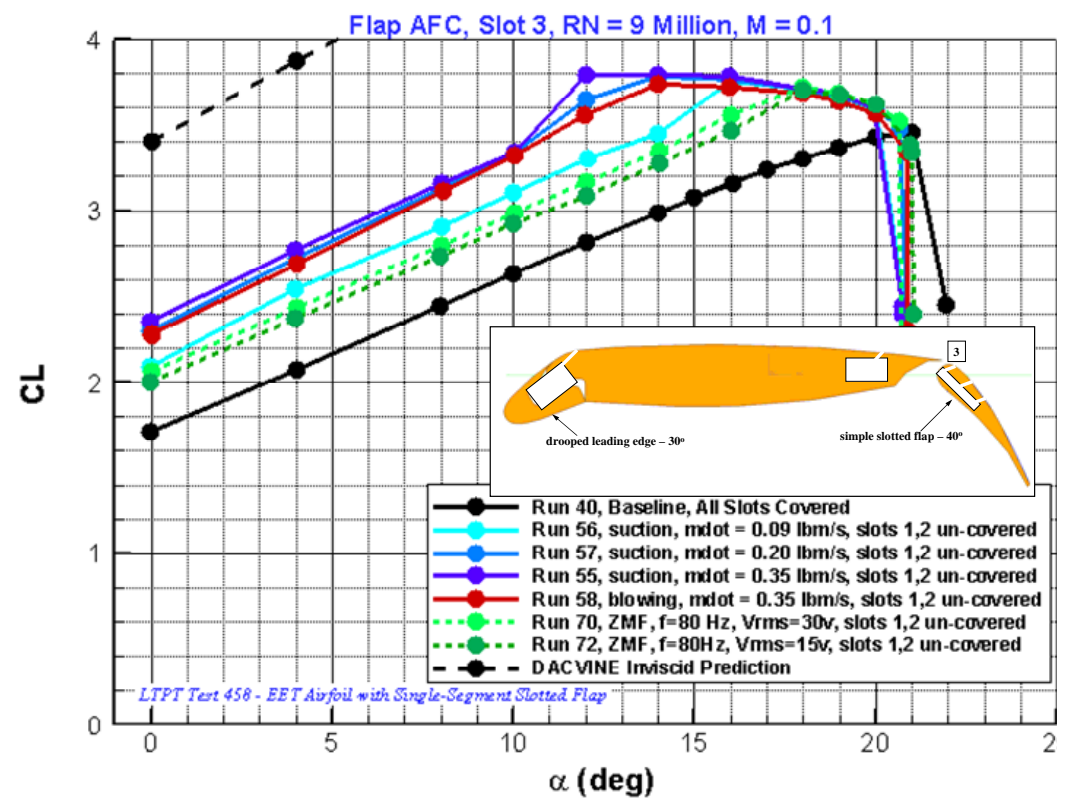

Figure 26. Lift performance of the EET high-lift configuration was significantly affected by the application of AFC from the first slot location on the flap.

Application of AFC was also evaluated through both first and second slots on the flap upper surface. The effect on lift performance is shown in Figure 27. Moderate amounts of suction from both slots significantly increase the lift performance (Run 65), while blowing - at even a higher mass flow rate - did little to increase the airfoil's lift performance (Run 64). The mass flow rate reported in this part of the experiment refers to the incoming flow to the plenum servicing all flap slots. The amount of mass flow rate at each individual slot exit on the flap is unknown.

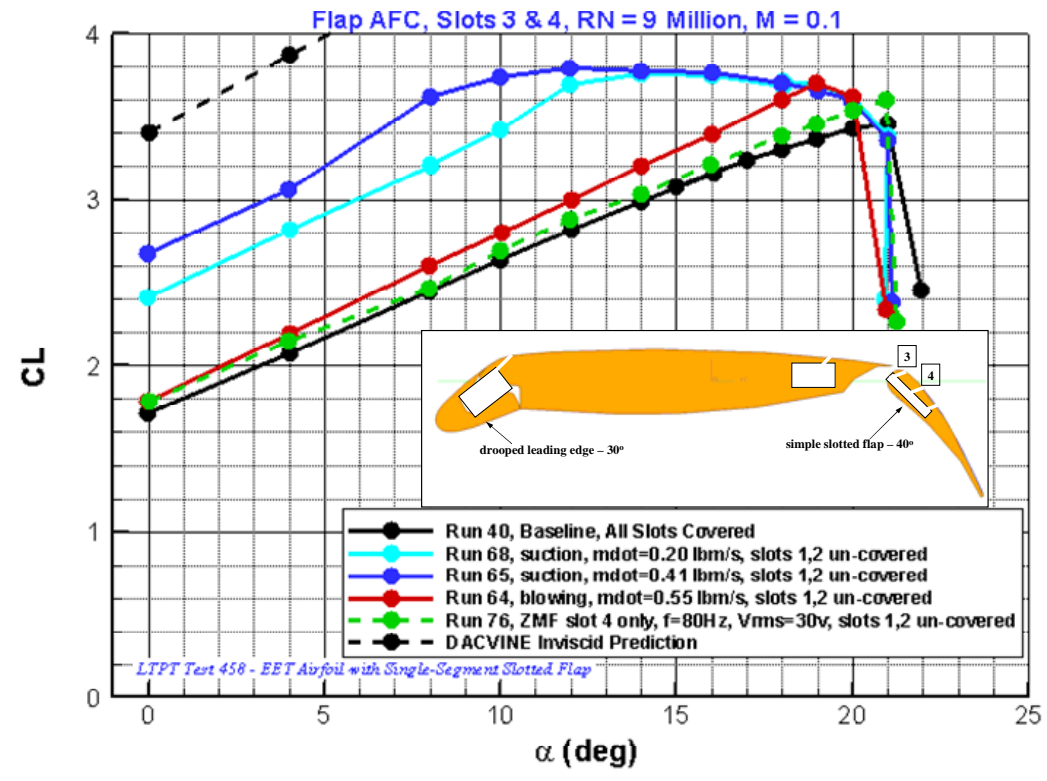

Figure 27. Addition of steady state AFC from the second flap slot had the most effect on the pre-stall lift performance. 
Overall, application of AFC from the flap second slot did not increase the maximum lift performance beyond what was attained with application of AFC from the first slot location on the flap, even though there was a noted increase in the lift levels in the pre-stall regime. As a result, and also due to the limited testing time, effect of application of AFC through the last slot on the flap was not investigated.

Flow Control Results - Leading Edge and Flap - The effect of AFC application to the leading edge of the main wing and the flap on the airfoil lift performance was examined during this wind tunnel test. AFC was applied to the main wing leading edge (slot 1 ) as well as the slots on the flap (slots 3 \& 4). Result of the measurements for steady suction and ZMF actuation on the main wing leading edge and flap are shown in Figure 28.

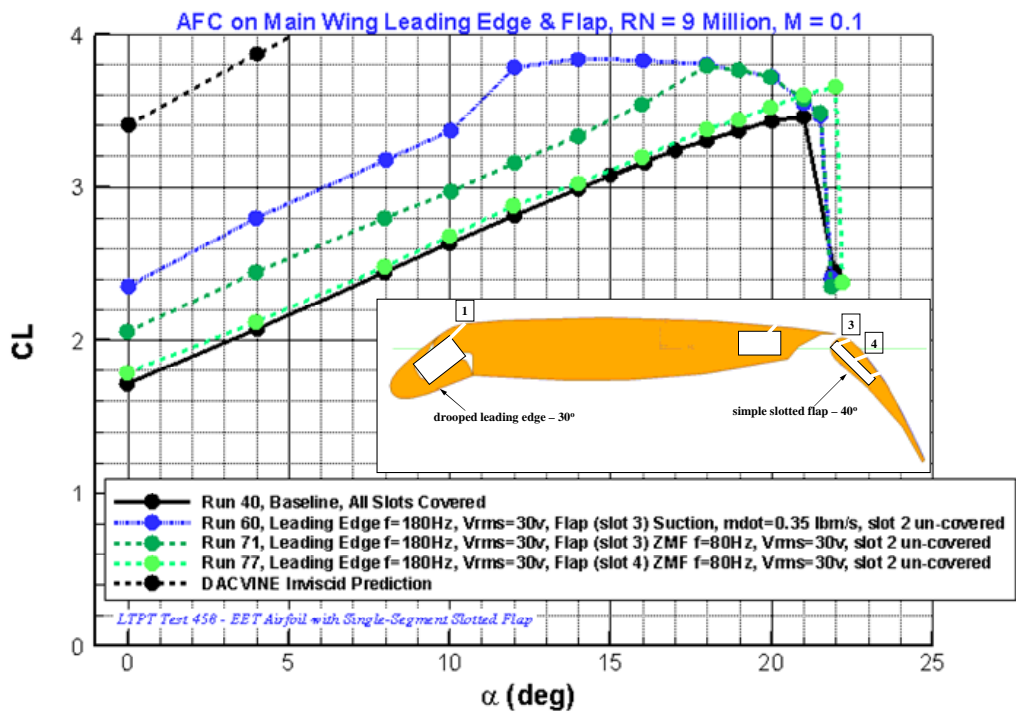

Figure 28. Application of leading edge ZMF AFC made the most difference in lift performance when steady state AFC was applied on the flap.

Among the combinations examined for this configuration, the one using steady suction on the flap provided the greatest lift benefit (Run 60). Application of AFC on the flap forward slot provided the greater lift benefit compared to the application from the middle slot (Runs $71 \&$ 77). This behavior was also evident when AFC was applied only to the flap (Run 76 in previous figure).

Flow Control Results - Main Wing Trailing Edge and Flap - The effect of AFC application to the main wing and the flap on the airfoil lift performance was examined during this wind tunnel test. AFC was applied to the main wing trailing edge (slot 2) as well as the slots on the flap (slots $3 \& 4$ ). Result of the measurements for steady suction and ZMF actuation on the main wing and flap are shown in Figure 29.

Application of steady suction on the main wing as well as two forward slots on the flap produced one of the highest lift enhancements on the EET high-lift configuration (Run 66). Application of ZMF AFC in any of the combinations examined during this wind tunnel test produced at most half of the lift enhancement obtained with steady AFC (suction). Due to the amount of testing time left during the LTPT entry, application of steady blowing was not investigated in this combination.

Flow Control Results - Leading Edge, Main Wing and Flap - The effect of AFC application to the leading edge of the main wing, the trailing edge of the main wing and the flap on the airfoil lift performance was examined during this wind tunnel test. AFC was applied to the main wing (slots 1 and 2), as well as the slots on the flap (slots $3 \& 4$ ). Result of the measurements for steady suction and ZMF actuation on the main wing leading edge and flap are shown in Figure 30. 


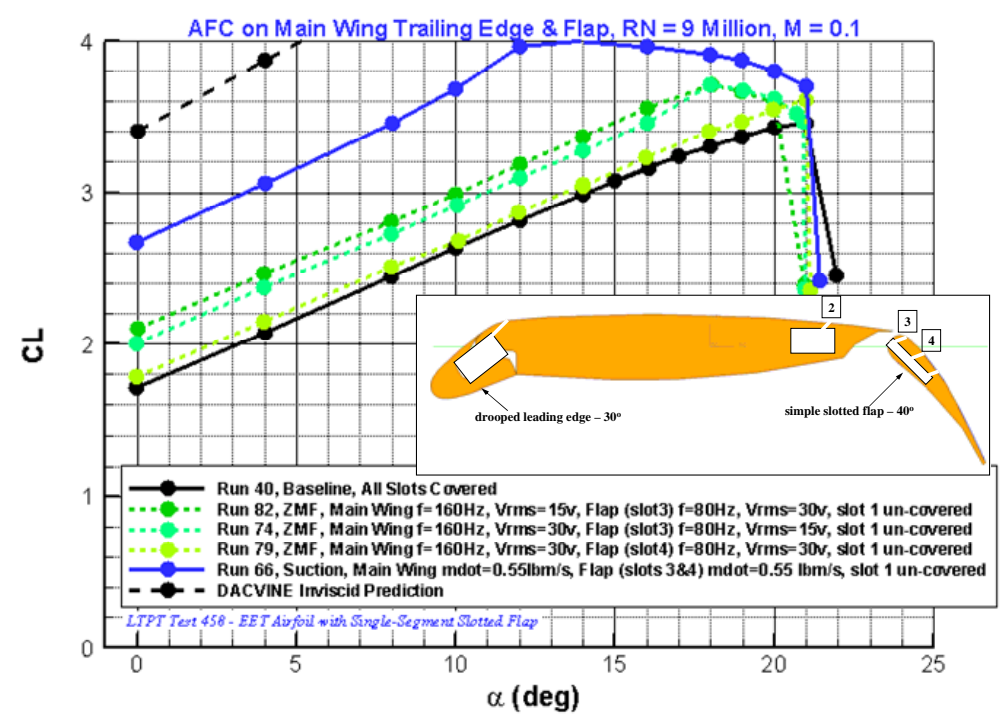

Figure 29. Application of main wing trailing edge AFC made the most difference in lift performance when steady state AFC was applied on the flap.

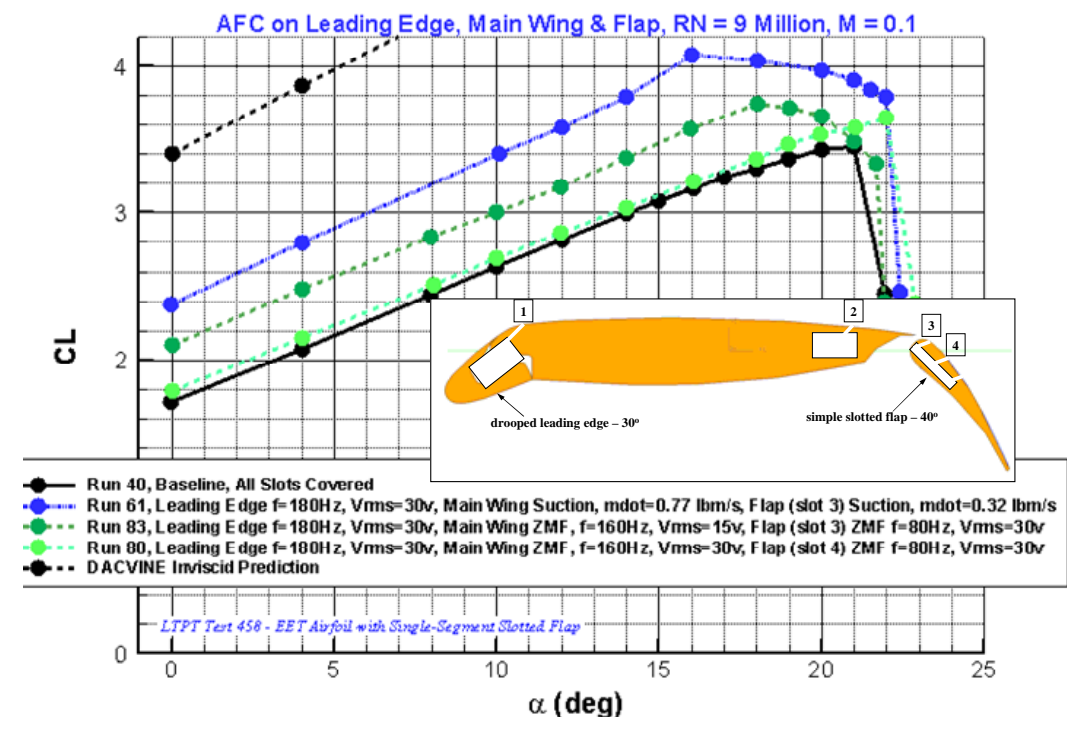

Figure 30. Maximum lift performance for this configuration was obtained with application of AFC on the leading edge, main wing trailing edge and the flap.

Among the combinations examined for this configuration, the one using steady suction on the flap provided the greatest lift benefit (Run 61). Application of ZMF AFC from all ports provided little lift enhancement (Run 80). Switching the flap ZMF AFC from the middle flap slot to the forward flap slot provided a noticeable increase in lift performance (Run 83). Application of steady AFC from the flap forward slot and the main wing trailing edge provided the greatest lift benefit observed during this test entry (Run 61).

The calibration data discussed in Section III of this paper can be used to estimate the total and individual $\mathrm{C}_{\mu}$ for this configuration. In the steady suction mode, the calibration data is limited to $0.18 \mathrm{lbm} / \mathrm{sec}$. Extrapolation of the calibration results, based on mass flow measurements, to the recorded mass flow rates for the actual test conditions indicate total $\mathrm{C}_{\mu} \sim 0.0178$ for the conditions attained in Run 61 .

Examination of pressure distributions from this configuration should provide some insight to the behavior observed in the integrated lift performance. This is particularly so, since all the open AFC slots are in operation and little or no concern should exist with regards to contamination from un-used and un-covered AFC slots. 
Representative pressure distributions for this configuration are shown in Figure 31 for 10 degrees angle of attack. The pressure distributions indicate that regardless of whether ZMF or steady AFC is applied, application from slot 3 location provides great benefits for the airfoil lift performance. The measured pressures indicate that application of AFC from slot 3 causes a large rise in pressure peak on the flap upper surface - to the point that the pressure peak helps "pump" the main wing and provide a high lift level despite the separated flow from the flap upper surface downstream of the peak suction. The large rise in peak pressure is far more pronounced for the steady suction case compared to the ZMF case for slot 3, when steady suction is combined with the main wing trailing edge. Similar behavior was observed in Figure 29 where application of steady suction at slot 2 and slot 3 (Run 66) provided large gains to the airfoil lift performance.

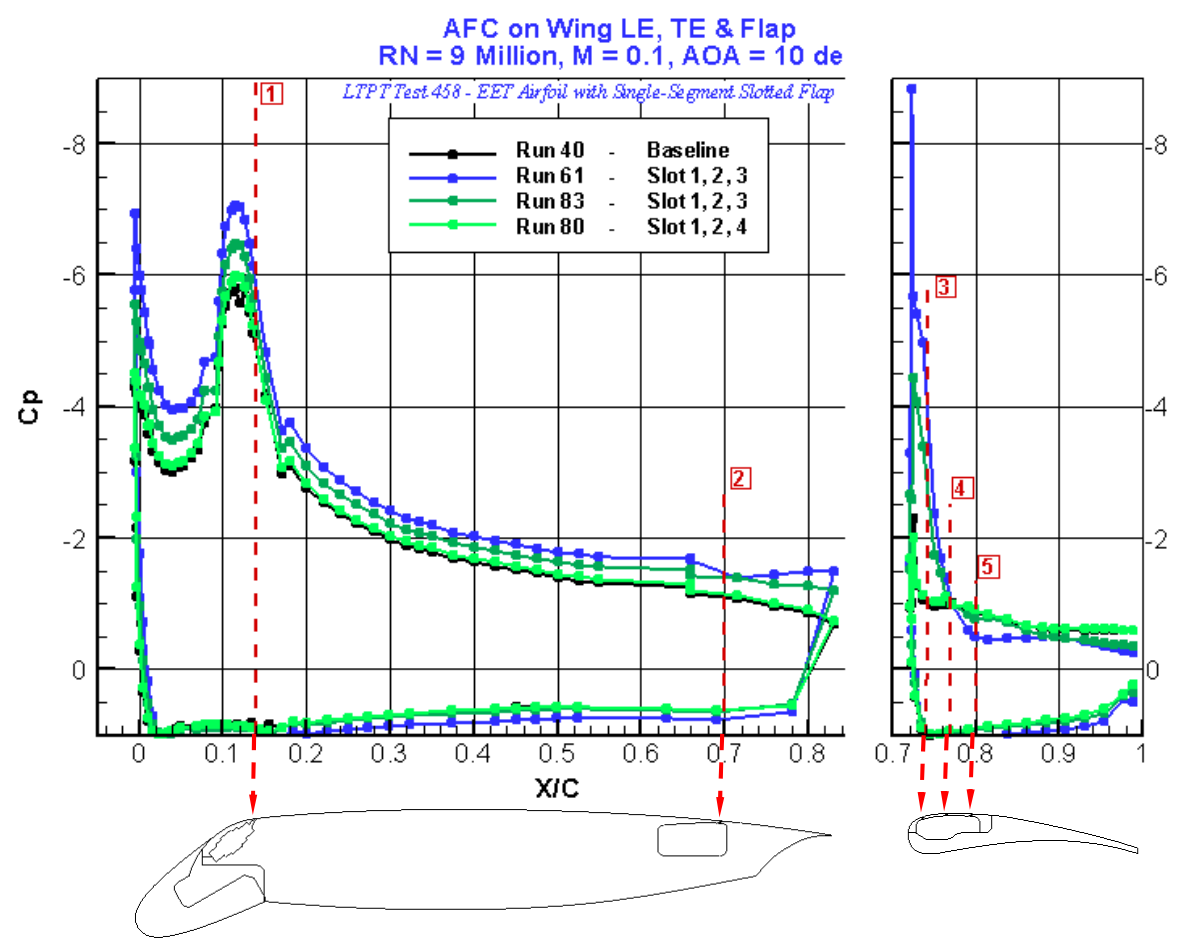

Figure 31. Application of steady blowing from slot 3 on the flap provides the largest lift increment among the configurations tested.

\section{Conclusions}

The results of a wind tunnel test conducted at NASA Langley's LTPT, on a high-lift model fitted with AFC actuators, were described and discussed in this paper. Several lessons were learned about application of AFC under high tunnel total pressures in order to simulate flight-scale conditions. They are summarized below:

1. Application of small amounts of suction and/or blowing at select locations on the EET high-lift airfoil provided appreciable gains in the lift performance. The limited post-test calibration of AFC actuators indicates maximum suction or blowing coefficients are consistent with the expected actuator maximum output values.

2. Exposure of airfoil AFC slots to the free-stream conditions can influence the measurement results. Comparison of measured surface pressures on the baseline configuration compared poorly when AFC slots were left un-covered. Application of tape to cover slots dramatically improved the lift performance repeatability. Several plausible explanations were provided in the text, all of which warrant further examination in future testing. As a result, for future comparison to computational results, only those runs should be selected where the un-used AFC slots were covered with tape. Researchers interested in the using the experimental data obtained during this program, should use Reference 12 to identify the set of measurements deemed reliable for comparison to computational results. 
3. Reynolds number effects on the performance of the high-lift airfoil configuration can be significant. The results from the baseline measurements are consistent with results obtained from similar measurements on other high-lift configurations. The results obtained with AFC applied at select location on the airfoil indicate RN effects can be quite significant. This finding is based on limited measurements made during this wind tunnel test program. Further measurements on similar high-lift configurations with AFC should be conducted to establish a broad base. These preliminary results suggest that testing and assessment of performance increments with application of AFC should be carried out at or near flight-scale conditions in order to adequately account for the AFC performance increments in the vehicle design process.

4. Application of steady AFC provided a greater influence on the airfoil performance than the application of ZMF AFC. The finding is based on the configuration tested during this study and the limited number of measurements. No measure of actuator power requirements are available at the present time for the actuation levels used during this study. Further assessment of both the actuation power requirement and advantages of steady-state AFC are recommended.

\section{Acknowledgement}

Implementation of the AFC hardware and conduct of this test would not have been possible without the dedication and hard work of the research staff at NASA Langley's Flow Physics and Control Branch as well as the staff operating the LTPT. The authors gratefully acknowledge the significant contributions of Mrs. Susan Gorton, Dr. John Lin, Mrs. Latunia Pack Melton, Mrs. Pamela Phillips, Dr. Norman Schaeffler and Mr. William Sewall of NASA Langley and Mr. Eric Dickey of Boeing. The funding for this study was provided by the Air Force Research Laboratory at Wright-Patterson Air Force Base, where contract monitors Dr. Angela Scribbens and Mr. Cale Zuene provided critical feedback during the course of this study.

\section{References}

1. Kiedaisch, J., Demanett, B. and Nagib, H., "Active Flow Control Applied to High-Lift Airfoils Utilizing Simple Flaps”, AIAA Paper 2006-2856, June 2006.

2. Seifert, A., and Pack, L. G., "Oscillatory Control of Separation at High Reynolds Numbers,” AIAA Journal, Vol. 37, No. 9, 1999, pp. 1062-1071.

3. Seifert, A., and Pack, L. G., "Active Control of Separated Flows on Generic Configurations at High Reynolds Numbers,” AIAA Paper 1999-3403, July 1999.

4. Pack, L. G., and Seifert, A., "Dynamics of Active Separation Control at High Reynolds Numbers," AIAA Paper 2000-0409, Jan. 2000.

5. Seifert, A., and Pack, L. G., "Separation control at flight Reynolds numbers - Lessons learned and future directions,” AIAA Paper 2000-2542, June 2000.

6. Seifert, A., and Pack, L. G., "Active Flow Separation Control on Wall-Mounted Hump at High Reynolds Numbers,” AIAA Journal, Vol. 40, No. 7, 2002, pp. 1363-1372.

7. Seifert, A., and Pack, L. G., "Compressibility and Excitation Location Effects on High Reynolds Numbers Active Separation Control,” Journal of Aircraft, Vol. 40, No. 1, 2003, pp. 110-119.

8. Seifert, A., and Pack, L. G., "Effects of Sweep on Active Separation Control at High Reynolds Numbers,” Journal of Aircraft, Vol. 40, No. 1, 2003, pp. 120-126.

9. Pack Melton, L, Schaeffler, N. W. and Lin, J. C., "High-Lift System For a Supercritical Airfoil: Simplified by Active Flow Control,” AIAA Paper 2007-707, January 2007.

10. Khodadoust, A. and Shmilovich, A., "High Reynolds Number Simulation of Distributed Active Flow Control for a High-Lift System," AIAA Paper 2007-4423, to be presented at the $25^{\text {th }}$ Applied Aerodynamics Conference, June 2007.

11. McLean, J. D., Crouch, J. D., Stoner, R. C., Sakurai, S., Seidel, G. E., Feifel, W. M. and Rush, H. M., "Study of the Application of Separation Control by the Unsteady Excitation to Civil Transport Aircraft,” NASA CR 1999-209338, June 1999. 
12. Khodadoust, A., "Final Report for Integrated Propulsion, Lift and Control System Optimization for Multi-Mission Mobility,” AFRL Contract F33615-00-D-3052 DO 0065, Boeing Document ASDM06-0001, May 2006.

13. McGhee, R. J., Beasley, W. D. and Foster, J. M., "Recent Modifications and Calibration of the Langley Low-Turbulence Pressure Tunnel,” NASA TP 2328, 1984.

14. Paschal, K., Goodman, W., McGhee, R., Walker, B, and Wilcox, P. A., "Evaluation of Tunnel Sidewall Boundary-Layer-Control Systems for High-Lift Airfoil Testing,” AIAA Paper 91-3242, September 1991.

15. Morgan Jr, H. L., "Experimental Test Results of Energy Efficient Transport (EET) High-Lift Airfoil in Langley Low-Turbulence Pressure Tunnel,” NASA TM-2002-211780, December 2002.

16. Woodward, D. S, Hardy, D. C., and Ashill, P. R., "Some Types of Scale Effect in Low-Speed HighLift Flows,” ICAS Paper 88-4.9.3, Presented at the $16^{\text {th }}$ ICAS Conference, Haifa, Israel, 1988. 